STRUCTURAL SCIENCE CRYSTAL ENGINEERING MATERIALS

ISSN 2052-5206

Received 18 June 2015

Accepted 28 September 2015

Edited by A. J. Blake, University of Nottingham, England

Keywords: high-pressure studies; MOFs; coordination polymers.

\section{Structural studies of metal-organic frameworks under high pressure}

\author{
Scott C. McKellar* and Stephen A. Moggach*
}

EaStCHEM School of Chemistry and the Centre for Science at Extreme Conditions, University of Edinburgh, Kings Buildings, West Mains Road, Edinburgh EH9 3JJ, Scotland. *Correspondence e-mail: scott.mckellar@ed.ac.uk, s.moggach@ed.ac.uk

Over the last 10 years or so, the interest and number of high-pressure studies has increased substantially. One area of growth within this niche field is in the study of metal-organic frameworks (MOFs or coordination polymers). Here we present a review on the subject, where we look at the structural effects of both non-porous and porous MOFs, and discuss their mechanical and chemical response to elevated pressures.

\section{Introduction}

Metal-organic frameworks (MOFs) are currently the subject of over a thousand research papers per year (Champness, 2011) and have attracted the attention of an incalculable number of research groups across the world. This is the result of a predisposition for structural diversity, tuneable properties and timely relevance to a range of technological applications.

MOFs, to use the definition by Cheetham and coworkers (Cheetham et al., 2006), are a subgroup of the family of solid materials known as hybrid inorganic organic frameworks, and are also referred to as coordination polymers or, occasionally, nanoporous hybrid frameworks.

The wide variety of terminologies and definitions used in this relatively young field of research led to the IUPAC setting up a task group to recommend a unified definition for MOFs. Initially they defined coordination polymer as 'a coordination compound with repeating coordination entities extending in one, two or three dimensions', and the subgroup of a coordination network as 'a coordination compound extending, through repeating coordination entities, in one dimension, but with cross-links between two or more individual chains, loops, or spiro-links, or a coordination compound extending through repeating coordination entities in two or three dimensions'. In a more general sense, MOFs are compounds consisting of metal ions or clusters (nodes) coordinated by organic linkers (struts) connected into framework architectures. MOFs are usually crystalline and highly porous, although amorphous and non-porous (dense) frameworks have been reported (Bennett, Goodwin et al., 2010; Xiao et al., 2009; Cheetham \& Rao, 2007). Metals used tend to be $d$-block elements, although there are many notable examples of aluminium-, gallium-, tin- and magnesium-based MOFs (Reinsch et al., 2012; Chaplais et al., 2009; Banerjee et al., 2011; Cheon et al., 2009; Dinca \& Long, 2005). Over the last two decades, this range of metals - in combination with a vast array of polyfunctional bridging ligands such as di- and tricarboxylic acids and imidazoles - has facilitated the synthesis of an enormous number of frame- 
works with a variety of porosities, functionalities and dimensionalities. Many have been subdivided into further categories (with acronyms based on chemical composition or geographical origin) such as isoreticular MOFs (IRMOFs), Matériaux de l'Institut Lavoisier (MILs) and zeolitic imidazolate frameworks (ZIFs).

Owing to this diversity, it is no surprise that MOFs have been studied across numerous scientific disciplines. To the synthetic chemist, the ability to tune the functionality and size of the framework pores by prior modification of the organic linker is one appealing avenue of research (Furukawa et al., 2013). Crystal engineering or isoreticular approaches to MOF synthesis can then enable systematic variation of pore size within libraries of frameworks (Eddaoudi et al., 2002). To the materials and applications scientist, the rational, targeted design of novel frameworks has revealed numerous potential applications in gas storage (Lin et al., 2007; Llewellyn et al., 2008), carbon capture (Nugent et al., 2013; Yang et al., 2012; Sumida et al., 2012), separation processes (Herm et al., 2011; Lu \& Hupp, 2010; Cychosz et al., 2010), molecular recognition (Chen et al., 2010; Lu et al., 2011; Kreno et al., 2012), heterogeneous catalysis (Lee et al., 2009), drug delivery (Horcajada et al., 2010), photochemistry (Allendorf et al., 2009; Blake et al., 2010; Lan et al., 2009) and magnetism (Zhang et al., 2007; Kurmoo, 2009). To the structural chemist and the crystallographer, the complex but beautiful architectures evident in many MOF materials has provided a rich source for exploration. It is on this latter theme that this review shall focus, specifically in terms of the effect of high pressure on the structure of MOFs.

It is worth first addressing the scope of the review. In addition to MOFs there is also, within the family of hybrid inorganic organic frameworks, a group of materials previously defined as extended inorganic hybrids (Cheetham et al., 2006). Systems in this category may well have $M-L-M$ connectivity like that found in MOFs, but are also characterized by inorganic substructures within the framework. Mostly, these substructures are composed of $M-\mathrm{O}-M$ arrays such as those found in hybrid metal oxides and other materials such as zeolites. There can be a certain degree of overlap between MOFs and extended inorganic hybrids, particularly in the case of porous hybrids with a three-dimensional $M-\mathrm{O}-M$ network (Vaidhyanathan et al., 2003; Guillou et al., 2003). The first such example reported, a nickel succinate hybrid (Forster \& Cheetham, 2002), has three-dimensional $\mathrm{Ni}-\mathrm{O}-\mathrm{Ni}$ bonding in addition to succinate-lined pores, creating a MOFlike assembly. Conversely, MIL-53 [MOH(BDC); $M=\mathrm{Al}, \mathrm{Cr}$, $\mathrm{Fe}, \mathrm{Ga}, \mathrm{In}, \mathrm{Sc} ; \mathrm{BDC}=1$,4-benzenedicarboxylate = terephthalic acid; Millange et al., 2002; Loiseau et al., 2004; Serre et al., 2002] is a MOF containing one-dimensional chains of octahedral metal cations bridged by corner-sharing hydroxide ions, which in some respects is similar to an extended inorganic hybrid. Although our review will focus specifically on highpressure studies of MOFs, relevant reports of high-pressure behaviour of inorganic hybrids or related materials will also be discussed to allow comparison. For the purposes of this work we will consider 'high pressure' to mean 'greater than 1000 atmospheres $(0.1 \mathrm{GPa})$ '. This is approximately the lower measurable pressure limit of a diamond-anvil cell (DAC), in which most high-pressure experiments on MOFs have been performed. This allows us to distinguish structural studies at high pressure from most typical gas adsorption studies of MOFs. Although gas adsorption measurements are conducted at elevated pressures, few are conducted above $100 \mathrm{~atm}$ (Li \& Yang, 2007; Millward \& Yaghi, 2005; Lin et al., 2007) due to the vapour pressure limits of common adsorption gases.

Pressure is a powerful thermodynamic variable, yet compared to temperature its effects have been little explored in chemical applications, particularly above $0.1 \mathrm{GPa}$. For molecular materials, temperatures can usually be varied within a few hundred degrees, whereas the difference between atmospheric pressure and $1 \mathrm{GPa}$ represents four orders of magnitude. $1 \mathrm{GPa}$ is actually rather modest by modern industrial standards: guacamole is processed at $0.8 \mathrm{GPa}$, for instance (Torres \& Velazquez, 2005). Understanding the response of MOFs to high pressure can be useful in several ways relevant to potential technological applications. Poor chemical and/or mechanical stability is one of the biggest practical problems associated with MOFs, and one which must be optimized for a framework to be considered useful. A good stability is often gauged by exposing a MOF to high temperatures (Cavka et al., 2008). However, high pressure is a useful tool to investigate not only the stability of a framework, but other important mechanical properties such as elasticity, stiffness, hardness and fracture toughness (Tan \& Cheetham, 2011). Gas storage agents are one of the most intensively studied MOF applications. Since gas sorption measurements are typically performed at pressures up to $0.01 \mathrm{GPa}$, and since many envisaged on-board gas storage systems are in pressurized environments, MOFs must be resilient to destructive structural distortion or pressure-induced amorphization. An excellent review by Tan \& Cheetham (2011) has previously discussed the mechanical properties and the effect of loading on hybrid inorganic organic framework materials. Such a discussion focused somewhat on hardness, plasticity and fracture behaviour but mainly on elasticity via assessment of Young's modulus (or elastic modulus, E; a measure of a material's stiffness under unidirectional loading), Poisson's ratio ( $v$; the ratio of transverse to axial strain, where compression in one direction is related to expansion in the perpendicular directions), bulk modulus ( $K$; the inverse of the compressibility and a measure of the mechanical resistance to volumetric changes under hydrostatic pressure) and shear modulus ( $G$; a material's stiffness under opposing and parallel shear forces). To use two examples given by the authors, such properties are important in the context of thin-film MOFbased structures in stress-induced chemical sensors (Allendorf et al., 2008), where stiffness and adhesion strength must be addressed to control plastic deformation and shear delamination, or in MOF coatings (Zacher et al., 2009; Ameloot et al., 2009) for catalytic applications, where a high thermal stability and fracture toughness is required to withstand stresses from high fluxes and temperatures. Although some of the concepts addressed by Tan and Cheetham will also be considered in this 
review, we will focus predominantly on structural, rather than mechanical, effects.

While techniques such as nanoindentation (Gouldstone et al., 2007; Tan, Furman \& Cheetham, 2009) and atomic force microscopy (Tan, Merrill et al., 2009) have been used effectively in the determination of elastic moduli and hardness properties, high-pressure X-ray crystallography (Katrusiak, 2008) is the formative experimental technique for analysing structure, compressibility and bulk moduli, and the one on which most of the following discussion is based. Recent results using high-pressure, single-crystal (Moggach, Bennett \& Cheetham, 2009; McKellar et al., 2014) and powder (Lapidus et al., 2013) X-ray diffraction (XRD) on MOFs have revealed, for instance, significant structural rearrangements such as ligand exchange and pore size/content modification. Such results have had a transformative effect on the discourse of high-pressure MOF research, which is still an emerging field and a relatively niche area of study. Until four or five years ago, there was essentially zero structural data on MOFs above $0.01 \mathrm{GPa}$. The novelty of the research topic has thus allowed us to provide, as far as we are aware, a comprehensive review of the literature at the time of writing.

For the analysis of materials under high pressure, a gasketed DAC is the standard piece of experimental equipment (Moggach, Allan et al., 2008). The Merril-Bassett DAC (Merrill \& Bassett, 1974) in particular is typical for diffraction and spectroscopic measurements. Solid samples, usually a single-crystal or polycrystalline powder, are loaded into a cylindrical hole in the gasket between the culets (flat faces) of the diamonds along with an internal pressure marker such as ruby (Piermarini et al., 1975) or quartz (Angel et al., 1997). A hydrostatic medium (a.k.a. pressure-transmitting liquid) is used to surround the sample and ensure uniform application of pressure before the cell is closed (Fig. 1). Pressure on the sample is then increased by turning screws which pull the diamonds closer together, up until a point when the sample degrades, splits apart, becomes amorphous or is otherwise rendered unsuitable for analysis. For many solid, non-porous materials for which high-pressure crystal structures have been

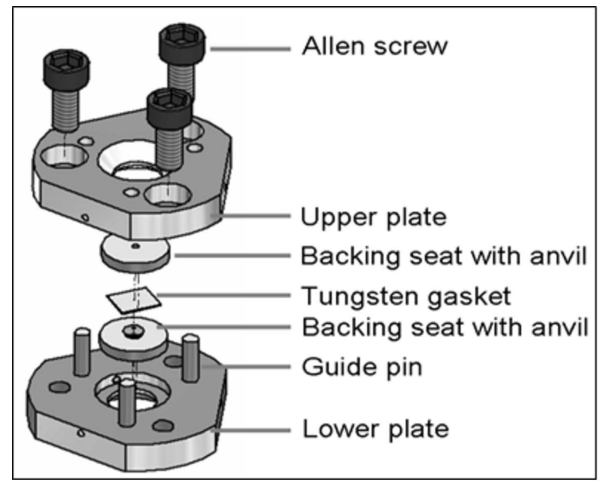

(a)

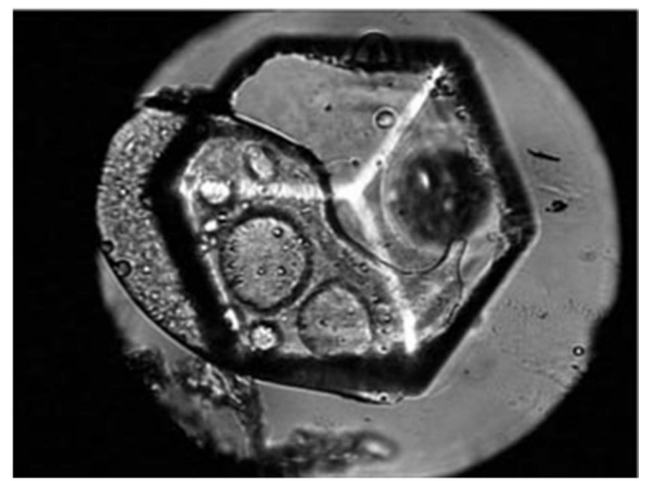

(b)
Figure 1

(a) Schematic of a modified Merrill-Bassett diamond-anvil cell (DAC) used in high-pressure singlecrystal X-ray diffraction experiments and $(b)$ an optical image of a single crystal of ZIF-8 at ambient pressure in a DAC (modified from Moggach, Bennett \& Cheetham, 2009). determined [e.g. molecular crystals (Moggach et al., 2005; Boldyreva et al., 2005), transition metal complexes (Byrne et al., 2012; Moggach, Galloway et al., 2009, Woodall et al., 2013; Parois et al., 2010) and single-molecule magnets (Prescimone et al., 2008, 2009)], the choice of hydrostatic medium used in the DAC is based on a consideration of the hydrostatic limit of the liquid and the solubility/reactivity of the sample. An ideal hydrostatic medium will remain fluid (or at least semihydrostatic) over the entire pressure range studied, and will not react with or dissolve the crystal. For instance, a 16:3:1 by volume mixture of methanol, ethanol and water (MEW) is a common medium and will remain hydrostatic until $c a 10 \mathrm{GPa}$ before freezing. If MEW reacts with the sample, a 1:1 mixture of $n$-pentane and isopentane, which has a hydrostatic limit of 7.4 GPa, may be a suitable alternative.

In porous materials such as MOFs, the hydrostatic medium can penetrate the pores and interact dynamically with the framework. Counterintuitively, this often causes the framework to expand when pressure is first applied. As pressure on a sample is increased, it can become superfilled (or hyperfilled) with liquid and this behaviour underpins many interesting results that have been observed in MOFs under pressure. Early work has shown that the structural response to pressure is highly sensitive to the choice of hydrostatic medium (Chapman et al., 2008). This has been augmented by more recent results which have demonstrated that the selection of a solvent used to apply pressure can no longer just be based arbitrarily on solubility and hydrostatic limit, but also on molecular size, shape and functionality (McKellar et al., 2014). Broadly speaking, hydrostatic media can be considered as being either penetrating or non-penetrating, although this classification is clearly dictated by the MOF pore size rather than the liquid itself. For nanoporous (pore diameter $<10 \AA$ ) MOFs, a small molecule such as methanol is a penetrating medium, while the bulkier molecule isopropyl alcohol (IPA) could be either penetrating or non-penetrating, depending on the exact pore channel dimensions. For larger microporous (10-20 ̊) MOFs, however, IPA is a penetrating medium. Long-chain and branched fluorinated hydrocarbons such as Fluorinert ${ }^{\circledR}$ FC-70 [perfluorotri$\mathrm{N}$-pentylamine $\left.\left(\mathrm{C}_{15} \mathrm{~F}_{33} \mathrm{~N}\right)\right]$ or FC77 [a mixture of perfluorooctane $\left(\mathrm{C}_{8} \mathrm{~F}_{18}\right)$ and perfluorooxacyclononane $\left.\left(\mathrm{C}_{8} \mathrm{~F}_{16} \mathrm{O}\right)\right]$ tend to be used as non-penetrating media in such cases. As the pore size is increased to mesoporous $(>20 \AA)$ however, even the largest Fluorinert liquid could of course be penetrating, although there are currently no high-pressure studies published on mesoporous materials.

The enormous variation of pore shapes and sizes is one advantage of MOFs over traditional porous metal-oxide or zeolite materials. 
One other advantage is that MOF frameworks are usually charge-neutral and thus host-guest interactions between the framework and, say, residual cavity-bound solvent are often weak. Solvent removal can give rise to permanent porosity and allow reversible guest uptake, which is a key facet of much interesting host-guest chemistry in MOFs (Kitagawa et al., 2004). This is in contrast to zeolites where a cationic skeleton can often collapse on solvent/guest removal due to stronger electrostatic host-guest interactions (Férey, 2008). Moreover, novel pressure-induced behaviour in MOFs is generally anticipated to occur at much lower pressures than in zeolites (Chapman \& Chupas, 2007) which by comparison have been investigated more extensively for their structural response to pressure (Hazen, 1983; Hazen \& Prewitt, 1977; Hazen \& Finger, 1984; Colligan et al., 2004; Haines et al., 2010). This is due to the greater porosities and elaborate connectivity in MOFs, which often result in frameworks with inherent flexibility and a tendency for more extreme and dramatic structural changes in response to pressure. The more moderate pressures required to produce a response in MOFs have allowed them to be studied at much lower, industrially achievable pressures ( $c a$ below $1 \mathrm{GPa}$ ), and in fact their highpressure behaviour can be highly relevant to their framework properties at ambient pressure.

For example, one fascinating phenomenon associated with some MOFs is breathing, where reversible changes in structure and volume occur in response to guest adsorption/desorption. Such behaviour may occur upon removal or sorption of the guest species under ambient conditions, or it can be initiated by some other external stimulus such as temperature, pressure or light. In a study of ZIF-8 [Zn(MeIm) $)_{2}$; MeIm $=2$-methylimidazolate], Moggach, Bennett \& Cheetham (2009) demonstrated that at $1.47 \mathrm{GPa}$, using methanol/ethanol as a hydrostatic liquid, the imidazolate rings rotate reversibly by $\sim 30^{\circ}$ to increase the cavity volume and allow more solvent into the framework. This high-pressure phase could in fact be used to model the breathing mechanism that occurs upon $\mathrm{N}_{2}$ adsorption in the same compound at ambient pressure (Fairen-Jimenez et al., 2011).

Breathing is directly linked to the framework flexibility and is associated predominantly with certain MIL and ZIF frameworks and other so-called third generation (Kitagawa \& Kondo, 1998) MOFs which can undergo reversible structure changes. Some of the volume changes observed in breathing modes can be staggering. MIL-53, for instance, can expand and contract by over $100 \%$ due to hinge-like movement of the BDC linking molecules at the coordination site of the metal cations. It has been demonstrated previously that MOFs exhibiting breathing effects may have a positive influence in gas storage applications (Férey, 2008; Fletcher et al., 2005; Zhao et al., 2004). MIL-53 has very high $\mathrm{H}_{2}$ and $\mathrm{CO}_{2}$ storage capacities and its contraction upon gas uptake at 5-6 atm. may have value in on-board gas storage technologies (Serre et al., 2007). Frameworks with sufficient flexibility can also admit over-sized guests due to the opening of the framework channel openings (windows) and/or cavities (Rosseinsky, 2004). For example, the one-dimensional $\mathrm{MOF} \mathrm{Ni}_{2}\left(4,4^{\prime} \text {-bipy }\right)_{3}$ (bipy $=$ bipyridine) has a window diameter roughly half the size of a toluene molecule, yet readily adsorbs this species because the windows are highly flexible and toluene is of an appropriate size to occupy the framework cavities. 1,3,5-Triethylbenzne, on the other hand, is too large for both the window and cavity and is thus excluded from the framework (Cussen et al., 2002).

Therefore, it can be said that flexibility and adsorption characteristics (including the size of the guest molecule) are the two key properties which inform the structural response of MOFs to external stimuli. Both can be investigated using highpressure diffraction experiments, which can push the uptake capacity and flexible regions of frameworks to their limits. Guests can be forced into unfavourable environments (e.g. hydrophilic molecules into hydrophobic pockets), oversized guests can be modelled in confined cavities and amorphization can be induced in crystalline compounds, causing a breadth of dynamic structural responses to be observed. Due to the amount of data that is lost in a high-pressure diffraction experiment (typically $30-40 \%$, from shading by the DAC) compared with an ambient-pressure experiment, high-pressure studies can also benefit hugely from complementary firstprinciples condensed matter simulations. This allows the potential energy landscape of MOFs to be explored and helps rationalize their structural behaviour.

In this review we will focus on key findings of high-pressure experiments on MOFs, encompassing the mechanical properties of framework structures, such as structural rearrangements, post-synthetic modification, the importance of hydrostatic media, adsorption sites and guest-guest and hostguest interactions. We shall also discuss how these factors affect framework compressibility, e.g. through the direction of compression, pressure-induced amorphization or negative linear compressibility. We do not discuss stereoelectronic effects on magnetic frameworks, such as spin-crossover or pressure-induced orbital reordering, with this review focusing almost entirely on paramagnetic or non-magnetic frameworks.

\section{Non-porous (dense) MOFs}

\subsection{Zeolitic and boron imidazolate frameworks}

As a means to introduce some fundamental aspects of highpressure MOF research, we start by discussing some of the work which has been performed on dense (non-porous) frameworks. Most published studies of non-porous MOFs have focused on the ZIF, ZIF-zni (Spencer et al., 2009) $\mathrm{Zn}(\operatorname{Im})_{2}(\operatorname{Im}=$ imidazolate $)$, with $z n i$ network topology (O'Keeffe et al., 2008) and its lithium-boron analogue, $\mathrm{LiB}(\mathrm{Im})_{4}$ (Bennett, Tan et al., 2010). Other more recent highpressure studies have also been performed on a number of one- and two-dimensional systems (Gould et al., 2014), although these have been discussed within other recent reviews (Tidey et al., 2014). Metal formates have also been extensively studied, with several studies published recently (Spencer et al., 2014; Mączka et al., 2014); although these are not discussed in detail here, some characteristic high-pressure behaviour of metal formates is discussed later (see $\$ 3$ ). 
To date, there have been several single-crystal high-pressure studies of ZIFs because of several factors. ZIF single crystals are usually chemically, thermally and mechanically stable (Park et al., 2006), easy to prepare, well ordered and highly symmetrical. The latter point is also true of many other MOFs and is highly advantageous in high-pressure research since less reciprocal space can be measured in the diffraction experiment, thus diminishing the problem of shading by the DAC.

ZIFs have tetrahedral metal centres (usually $\mathrm{Zn}^{2+}$ or $\mathrm{Co}^{2+}$ ) coordinated via nitrogen at the 1,3-positions on Im-based linking molecules. The subtended $M-\operatorname{Im}-M$ bond angle is $145^{\circ}$ - analogous to the $\mathrm{Si}-\mathrm{O}-\mathrm{Si}$ angle in silicates and zeolites - creating topological similarities to zeolites from which their name derives, but with a much broader range of possible structures due to the diversity of functionalized Im linkers (Huang, Lin et al., 2006).

ZIF-zni (Lehnert \& Seel, 1980) is the most stable (Lewis et al., 2009; Baburin et al., 2008) and dense ZIF reported. The framework is essentially non-porous: the cavities are too small to host any solvent molecules and are therefore empty. Spencer et al. (2009) were the first to report its unique highpressure structural behaviour. They found that, using IPA as a non-penetrating medium in a single-crystal XRD experiment, ZIF-zni undergoes a phase transition between 0.54 and $0.85 \mathrm{GPa}$. This transition proceeds via a destructive singlecrystal to single-crystal (SC-SC) transformation and is attributed to a complex cooperative bond rearrangement (Fig. 2). This facilitates the formation of a denser high-pressure phase with a corresponding drop in space-group symmetry from $I 4_{1} c d$ to $I 4_{1}$. The bulk modulus $(K)$ of ZIF-zni was also estimated to be $\sim 14 \mathrm{GPa}$. For comparison, $K$ values are typically < $30 \mathrm{GPa}$ for molecular solids and 19-59 GPa for zeolites. Tan et al. (2010) have subsequently investigated the mechanical properties of ZIF-zni and six other porous ZIFs using a nanoindentation approach which confirmed that elastic properties are correlated non-linearly to density and porosity. Being the densest, it is perhaps no surprise then that ZIF-zni has the highest bulk and elastic moduli (i.e. stiffness; $E$ $\simeq$ 8-9 GPa) of any member of the ZIF family. A related finding from this work is the presence of elastic anisotropy due to the tetragonal symmetry of ZIF-zni. Distinct $E$ values in the (001) and (100) facets indicate that the stiffest orientation is that parallel to the $c$-axis (along the length of the narrow onedimensional framework 'channels'). This could explain why the high-pressure compression observed during the phase transition of ZIF-zni in IPA occurs principally within the $a b$ plane (Spencer et al., 2009); there is a 3.2\% decrease in the length of the $a / b$ axes, and a $4.5 \%$ increase in length of the $c$ axis.

Elastic anisotropy is a common theme which emerges upon loading of both porous and non-porous MOFs and other framework materials. It is an important property to understand in the context of useful negative linear compressibility (NLC) materials (see \$3), for instance. This behaviour can be directly attributed to the underlying architectures which are stiffer or more compressible in certain directions. This has been illustrated nicely by a study of the two polymorphs of copper phosphonacetate (CuPA; Tan, Merrill et al., 2009). The first polymorph, CuPA-1, is a three-dimensional framework containing $\mathrm{Cu}-\mathrm{O}-\mathrm{Cu}-\mathrm{O}-\mathrm{Cu}-\mathrm{O}-\mathrm{P}-\mathrm{O}-\mathrm{Cu}$ chains along the $a$ axis and phosphonate and carboxylate ligands extending the structure in the other two dimensions. Due to the rigid inorganic chains along the $a$-axis, the (100) facet is the stiffest ( $E \simeq$ $93 \mathrm{GPa}$ ). CuPA-2, by contrast, is a two-dimensional layered structure in the $a c$ plane, with hydrogen bonding between adjacent layers extending along the $b$-axis. As such the (100) and (001) oriented facets have elastic moduli of 61 and $55 \mathrm{GPa}$, respectively, while the (010) facet is approximately half this value due to the comparatively weaker, and thus more compressible, hydrogen bonds.

The high-pressure work on ZIF-zni was extended by Bennett and co-workers (Bennett, Tan et al., 2010) who performed high-pressure and mechanical experiments on crystals of the isostructural boron imidazolate framework (BIF), $\mathrm{LiB}(\mathrm{Im})_{4}$, in a study which serves as a useful example of how high pressure can be used to compare the effect of metal substitution on mechanical properties. BIFs (Zhang, Wu et al., 2009; Wu et al., 2009) are lightweight structural analogues of ZIFs in which zinc cations are alternately replaced by lithium and boron. Given that both ZIF-zni and $\mathrm{LiB}(\mathrm{Im})_{4}$ are

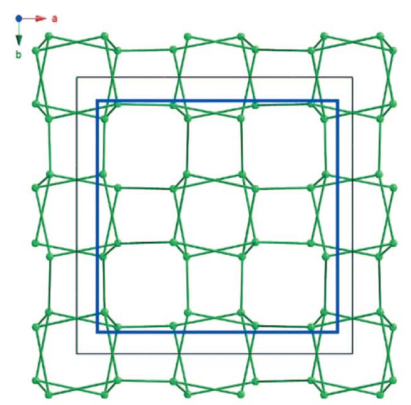

(a)

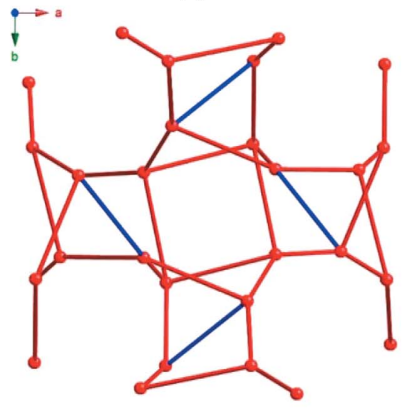

(c)

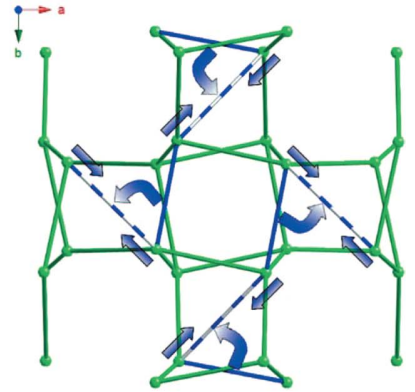

(b)

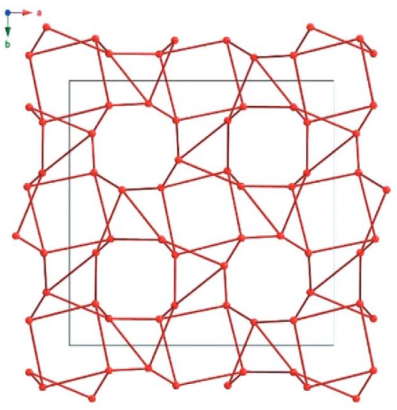

(d)
Figure 2

(a) Ball-and-stick representation of the $\mathrm{ZnIm} \alpha$-phase; the $\mathrm{Zn}^{2+}$ cations are shown as balls and the imidazolate ions as sticks. (b) A close-up of the structure within the blue square displayed in Fig. 2(a). This diagram shows the cooperative bond rearrangement that occurs during the $\alpha$ to $\beta$ phase transition. The solid blue lines are the links that are broken during the transition, and the blue and white stripped lines show the locations where the imidazolate links are reformed. (c) The ZnIm $\beta$-phase. The blue lines show the new positions for the imidazolate links that moved during the transition. (d) Ball-and-stick representation of the $\mathrm{ZnIm} \beta$ phase. Reprinted with permission from Spencer et al. (2009). Copyright (2009) American Chemical Society. 
isostructural, there are some remarkable differences between the two materials. Performing XRD on a single crystal of $\mathrm{LiB}(\mathrm{Im})_{4}$ in IPA, a phase transition was detected at $1.69 \mathrm{GPa}$. The crystal structure of the new phase could not be solved, so we can only speculate if the high-pressure phase of $\mathrm{LiB}(\mathrm{Im})_{4}$ is isostructural to the high-pressure phase of ZIF-zni. It is notable, however, that this pressure is double that at which the transition was induced in ZIF-zni. The bulk modulus of $\mathrm{LiB}(\mathrm{Im})_{4}$ was calculated to be $16.6 \mathrm{GPa}$, which is larger than the $14 \mathrm{GPa}$ reported for ZIF-zni, indicating that despite its lower density $\mathrm{LiB}(\mathrm{Im})_{4}$ is the less compressible of the two. Contrary to this though, the authors also note that the elastic modulus of $\mathrm{LiB}(\mathrm{Im})_{4}$ is substantially lower $(E=2.7-3.3 \mathrm{GPa})$ and thus the $\mathrm{Zn}-\mathrm{Im}-\mathrm{Zn}$ bonds of ZIF-zni are much stiffer than the $\mathrm{Li}-\mathrm{Im}-\mathrm{B}$ bonds in $\mathrm{LiB}(\mathrm{Im})_{4}$. It was clearly established that the flexibility of the metal coordination polyhedra was of the order $\mathrm{LiN}_{4}>\mathrm{ZnN}_{4}>\mathrm{BN}_{4}$ and, therefore, the higher bulk modulus of $\mathrm{LiB}(\mathrm{Im})_{4}$ is because of its smaller pore volume (solvent accessible volume $=5.3 \%$; $c f$. $12.2 \%$ for ZIFzni) in spite of the more flexible nature of the $\mathrm{LiN}_{4}$ environment (Bennett, Tan et al., 2010).

\subsection{Generation of porosity in $\mathrm{Zn}(\mathrm{CN})_{2}$}

$\mathrm{Zn}(\mathrm{CN})_{2}$ (Williams et al., 1997) is comprised of tetrahedrally coordinated zinc ions bridged linearly by disordered cyanide anions to form a MOF-like molecular framework with diamondoid topology (O'Keeffe et al., 2008). It is doubly interpenetrated - a feature fundamentally at odds with most potential MOF applications since it removes porosity from the structure. Lapidus et al. (2013), however, recently reported four new crystalline phases of $\mathrm{Zn}(\mathrm{CN})_{2}$, resolved using highpressure powder XRD. The novel forms were obtained as structural transitions in response to compression using different hydrostatic media. Most notably, the interpenetration in the native $\operatorname{Pn} \overline{3} m$ structure can be eliminated when a water- or methanol-containing fluid is used. Compressed in water/IPA mixtures at $\sim 1.2 \mathrm{GPa}$, the framework adopted the diamondoid structure observed in the native form but with no interpenetration, while in MEW at $\sim 1.2 \mathrm{GPa}$ the framework rearranged to a $P 6_{3} / m m c$ non-interpenetrated lonsdaleite (O'Keeffe et al., 2008) structure through different orientations

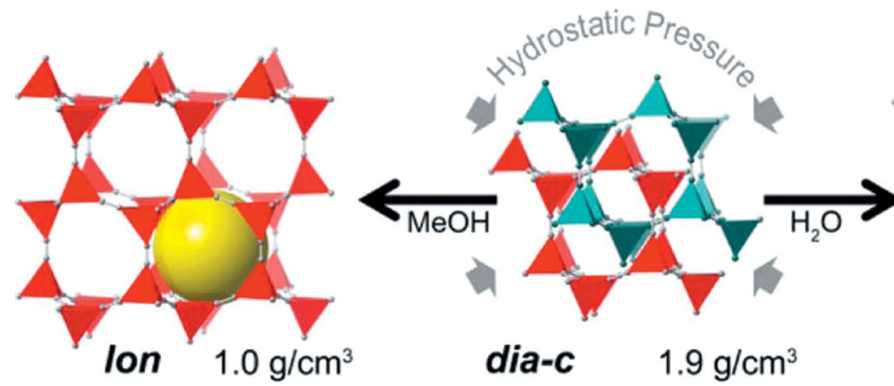

Figure 3

Hydrostatic fluid-dependent phase transitions in the doubly penetrated diamondoid framework (dia-c) of $\mathrm{Zn}(\mathrm{CN})_{2}$ to porous non-interpenetrated polymophs diamondoid (dia- $\left.\mathrm{Zn}(\mathrm{CN})_{2}, F d 3 m\right)$ and londaleite (lon- $\left.\mathrm{Zn}(\mathrm{CN})_{2}, P 6_{3} / m m c\right)$. Reprinted from Lapidus et al. (2013). Copyright (2013). American Chemical Society. of the $\mathrm{Zn}(\mathrm{CN})_{4}$ tetrahedra (Fig. 3). This latter transition was alluded to in a previous publication (Poswal et al., 2009), although no structures were reported. In the new diamondoid and lonsdaleite phases the frameworks are porous, with a density of $\sim 1.0 \mathrm{~g} \mathrm{~cm}^{-3}$; approximately half that of the native $\mathrm{Zn}(\mathrm{CN})_{2}\left(\rho=1.9 \mathrm{~g} \mathrm{~cm}^{-3}\right)$. The total void volume is $\sim 60 \%$ of the total crystal volume and the cavity diameter is $\sim 6 \AA$. In each case the voids are occupied with the molecules from the hydrostatic medium. This work is a good example of the sensitivity of frameworks to the choice of hydrostatic medium. As the authors point out, comparable ambient-pressure behaviour is observed in the $\mathrm{Cd}(\mathrm{CN})_{2}$ clathrates (Iwamoto, 1996; Kitazawa et al., 1995). These structural analogues of the two new $\mathrm{Zn}(\mathrm{CN})_{2}$ phases are synthesized directly with molecules from the solvent included as guests, with different solvents or solvent mixtures favouring different framework topologies. For instance, tetrahedral guests (e.g. $\left.\mathrm{CCl}_{4}, \mathrm{CHCl}_{3}\right)$ promote the diamondoid $\mathrm{Cd}(\mathrm{CN})_{2}$, while bulkier guests promote the lonsdaleite topology.

The non-interpenetrated $\mathrm{Zn}(\mathrm{CN})_{2}$ structures are stable upon the release of pressure and, in the case of the lonsdaleite structure, removal of the guest molecules. The authors attribute this porosity-generating behaviour to inefficient space filling by the interpenetrated diamondoid $\mathrm{Zn}(\mathrm{CN})_{2}$, allowing liquid to be forced into the otherwise non-porous framework and facilitating the major bond rearrangements necessary to generate the non-interpenetrated phases. Assuming that inefficient space filling is a common characteristic in interpenetrated systems, this work may have interesting implications in many large-pore MOF materials which are already the subject of numerous strategies to control interpenetration (Shekhah et al., 2009; Zhang, Wojtas et al., 2009; Bureekaew et al., 2010; Lun et al., 2011).

\section{Negative linear compressibility}

In addition to the behaviour outlined above, $\mathrm{Zn}(\mathrm{CN})_{2}$ and other cyanide-based frameworks are exemplars of another intriguing mechanical phenomenon: negative linear compressibility (NLC; Baughman et al., 1998). On compression of a crystal under hydrostatic pressure, one may expect a reduction of all three of its unit-cell dimensions, however, there are a number of compounds that instead expand along one or more directions. Materials displaying this NLC currently attract much attention due to their potential in piezoresponsive applications such as pressure sensors and 'smart' body armour (Evans \& Alderson, 2000; Baughman, 2003; Grima et al., 2011).

High-pressure diffraction experiments can quantify linear compressibility in $\mathrm{TPa}^{-1}$ by defining the relative rate of change in dimension $l$ with pressure at 
constant temperature [isothermal compressibility, $K_{1}=$ $-(\delta(\ln l) / \delta p)_{T}($ Goodwin, Keen et al., 2008)]. Typical values for crystalline materials over a specified pressure range are 5$50 \mathrm{TPa}^{-1}$, where a lower value signifies a stiffer, less compressible material and a higher value one which is softer and more compressible. For NLC materials, $K$ is negative in certain directions. Although NLC has been reported in inorganic molecules (Baughman et al., 1998; Mariathasan et al., 1985; Haines et al., 2003), organic molecules (Fortes et al., 2011) and transition metal complexes (Woodall et al., 2013; Shepherd et al., 2012), the largest NLC effects by far have been observed in framework materials. Indeed, Baughman et al. (1998) identified the wine-rack framework connectivity as one in which NLC behaviour can be expected to some degree. In this respect then, the phenomenon of NLC is actually fairly intuitive: if a wine-rack is compressed in the vertical direction, it must expand along the horizontal direction. NLC materials are interesting because they display this behaviour under hydrostatic compression.

Negative thermal expansion (NTE) is a physiochemical effect which causes a material to contract upon heating. It is now established that frameworks with strong anisotropic NTE behaviour are also likely to show pronounced NLC (Goodwin, Keen et al., 2008; Fortes et al., 2011; Cairns \& Goodwin, 2015). The two phenomena are not thermodynamically linked, but are related by moiety flexibility favoured by both conditions.

\subsection{Metallocyanides}

Above $1.5 \mathrm{GPa}, \mathrm{Zn}(\mathrm{CN})_{2}$ undergoes a symmetry-breaking phase transition and from 1.5-5.0 GPa displays NLC along the $a$-axis (Collings et al., 2013). This, and the significant NTE also apparent in $\mathrm{Zn}(\mathrm{CN})_{2}$, are due to bending distortions in the flexible $\mathrm{Zn}-\mathrm{CN}-\mathrm{Zn}$ moiety (Chapman \& Chupas, 2007). These authors showed how the degree of NTE in $\mathrm{Zn}(\mathrm{CN})_{2}$ is enhanced by pressure, specifically noting that the bulk modulus decreases, while the coefficient of thermal expansion becomes more negative, with increasing pressure. This suggests that the phonon modes responsible for NTE (Barrera et al., 2005) are also those that cause the material to become softer and are responsible for NLC on compression (Collings et al., 2013). In a further study of $\mathrm{Zn}(\mathrm{CN})_{2}$, Collings et al. (2013) demonstrated that the structural rearrangements at high pressure (concerted tilting of columns of $\left[\mathrm{Zn}(\mathrm{C} / \mathrm{N})_{4}\right]$ tetrahedra) establishes the dominant form of vibrational motion also responsible for NTE in the ambient-pressure phase (Goodwin \& Kepert, 2005; Chapman et al., 2005). The authors also investigated the $\mathrm{ZIF} \mathrm{Cd}(\mathrm{Im})_{2}$, which is isostructural to $\mathrm{Zn}(\mathrm{CN})_{2}$. Results revealed that pressure-induced distortions in $\mathrm{Zn}(\mathrm{CN})_{2}$ mirror the structural effect of cooling $\mathrm{Cd}(\mathrm{Im})_{2}$ (Collings et al., 2013). The analogous critical behaviour here shows that in molecular frameworks the thermodynamics of NTE and NLC are governed primarily by packing efficiency.

Further metallocyanide frameworks have been investigated by Goodwin and co-workers who report very large NLC in $\mathrm{Ag}_{3}\left[\mathrm{Co}(\mathrm{CN})_{6}\right]$ (Goodwin, Keen et al., 2008; $K=-75 \mathrm{TPa}^{-1}$ until a phase transition at $0.19 \mathrm{GPa}$, and $K=-5 \mathrm{TPa}^{-1}$ thereafter) and an even larger NLC in the structurally analogous $\mathrm{KMn}\left[\mathrm{Ag}(\mathrm{CN})_{2}\right]_{3} \quad$ (Cairns et al., 2012; $K=$ $-12 \mathrm{TPa}^{-1}$ from 0 to $2.2 \mathrm{GPa}$ ), both of which also display extreme NTE (Goodwin, Calleja et al., 2008) along the same directions as the NLC. In both cases this is attributed to covalent bonds which act as hinges in the wine-rack analogy, where the dimensions of the flexible cyanide lattice are dictated by low-energy $\mathrm{Ag}^{+} \cdots \mathrm{Ag}^{+}$(argentophilic) interactions. Wine-rack structural distortions are also responsible for the recently reported NLC behaviour in $\mathrm{Co}(\mathrm{dca})_{2}(\mathrm{dca}=$ dicyanamide), which also undergoes a phase transition from an orthorhombic to monoclinic phase at $1.1 \mathrm{GPa}$. The NLC here is only modest, however $\left[K=-3.7\right.$ (3) $\mathrm{TPa}^{-1}$; Yakovenko et al., 2015]. Recently, the largest and most persistent NLC ever published was reported in the framework $\mathrm{Zn}\left[\mathrm{Au}(\mathrm{CN})_{2}\right]\left[K=-42(5) \mathrm{TPa}^{-1}\right.$, where $0<p<1.8 \mathrm{GPa}$, Fig. 4; Cairns et al., 2013]. Here, a large uniaxial expansion of the honeycomb structure occurs along the $c$-axis, in a similar fashion to that observed in other similar structures. However, there is a cross-bracing effect in the perpendicular direction, with helical aurophilic $\left(\mathrm{Au}^{+} \cdot \cdots \mathrm{Au}^{+}\right)$chains acting as springs which contract under pressure and enhance the NLC effect (Fig. $4 b$ ). The authors also note that the spring-like response in $\mathrm{Zn}\left[\mathrm{Au}(\mathrm{CN})_{2}\right]$ is specifically a pressure-induced mechanism, so although there is an NTE effect apparent in the framework it is comparatively less extreme than the NLC. Although the contraction with heating and expansion with compression observed in these examples of NTE and NLC typically occur along the same direction, Cai \& Katrusiak (2014) have recently shown that this is not always the case. In the compound $[\mathrm{Ag}$ (ethylenediamine) $] \mathrm{NO}_{3}$, the authors show that the two phenonmena occur in perpendicular directions due to positive coupling between thermal crystal expansivity and compressibility as a result of void-filling $\mathrm{NO}_{3}^{-}$anions.

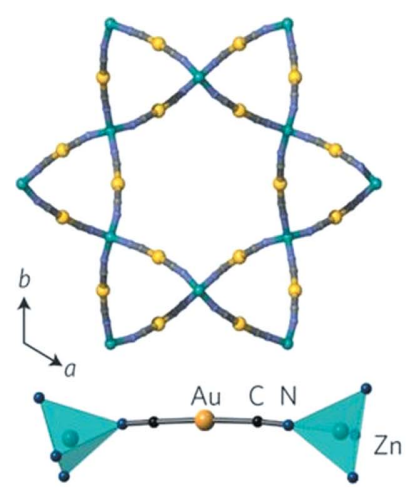

(a)

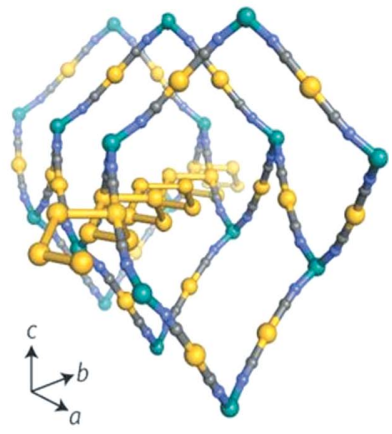

(b)
Figure 4

(a) One of the six $\beta$-quartz-like nets of $\mathrm{Zn}\left[\mathrm{Au}(\mathrm{CN})_{2}\right]_{2}$ viewed down its crystallographic $c$-axis; this framework consists of $\mathrm{ZnN}_{4}$ tetrahedra connected via flexible dicyanoaurate $(\mathrm{N}-\mathrm{C}-\mathrm{Au}-\mathrm{C}-\mathrm{N})$ molecular linkers. (b) An alternate view that highlights the honeycomb-like nature of its hexagonal pores and also the cross-bracing effect of helical aurophilic chains running perpendicular to the $c$ crystal axis. Figure adapted from Cairns et al. (2013). 


\subsection{Classical MOFs}

Given the structural variability, inherent flexibility and NTE observed in prototypical MOFs such as MOF-5 [a.k.a. IRMOF1; $\mathrm{Zn}_{4} \mathrm{O}(\mathrm{BDC})_{3}$ ] and HKUST-1 [a.k.a. Cu-BTC; $\mathrm{Cu}_{3}(\mathrm{BTC})_{2}\left(\mathrm{H}_{2} \mathrm{O}\right)_{3} ; \mathrm{BTC}=1,3,5$-benzenetricarboxylate; $\mathrm{Wu}$ et al., 2008; Lock et al., 2010; Dubbeldam et al., 2007; Peterson et al., 2010; Han \& Goddard, 2007] and more recently MIL-53 (Serra-Crespo et al., 2015) it is unsurprizing that huge NLC has also been reported in some MOFs. In fact, almost all highpressure diffraction experiments on porous MOFs reveal volumetric expansion to some extent at lower initial pressures, when a penetrating medium is used (Moggach, Bennett et al., 2009; Chapman et al., 2008; Graham et al., 2011). However, this behaviour results from swelling due to pressure-induced guest uptake and not necessarily an intrinsic NLC effect (i.e. with a non-penetrating medium). Under the 'classical' definition of a MOF, there are currently four reported to exhibit significant NLC: $\operatorname{Ag}(\mathrm{MeIM})$ (Ogborn et al., 2012), the zinc formate $\left[\mathrm{NH}_{4}\right]\left[\mathrm{Zn}(\mathrm{HCOO})_{3}\right] \quad(\mathrm{Li}$ et al., 2012), ZAG-4 $\left[\mathrm{Zn}\left(\mathrm{HO}_{3} \mathrm{PC}_{4} \mathrm{H}_{8} \mathrm{PO}_{3} \mathrm{H}\right)\right.$; Gagnon et al., 2013] and ZAG-6 $\left[\mathrm{Zn}\left(\mathrm{HO}_{3} \mathrm{PC}_{6} \mathrm{H}_{12} \mathrm{PO}_{3} \mathrm{H}\right.\right.$; Ortiz et al., 2014]. The preceding discussion of metallocyanide frameworks is useful in highlighting the fundamental properties governing this behaviour in framework materials. Indeed, in their discussion of $\mathrm{Ag}(\mathrm{MeIM})$ (Huang, Li et al., 2006), Ogborn et al. (2012) note that the increasing frequency with which framework materials are found to exhibit anomalous mechanical behaviour infers the existence of common structural features which are ultimately responsible for similar effects in other materials.

$\mathrm{Ag}(\mathrm{MeIM})$ displays a NLC of $-4.32 \mathrm{TPa}^{-1}$ along the $c$-axis from 0 to $1 \mathrm{GPa}$ before reverting to positive linear compres-
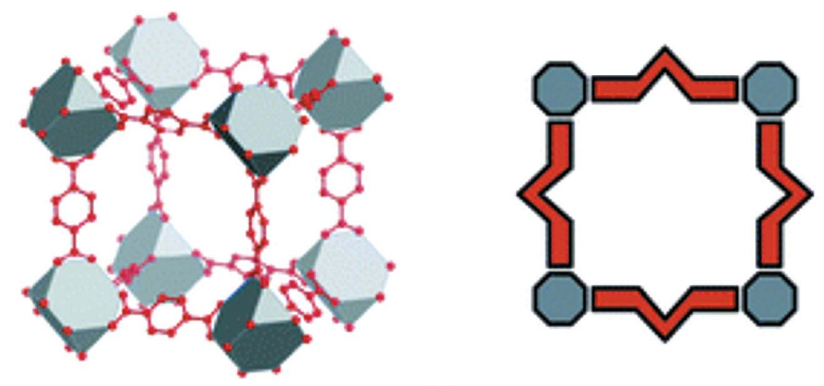

(a)
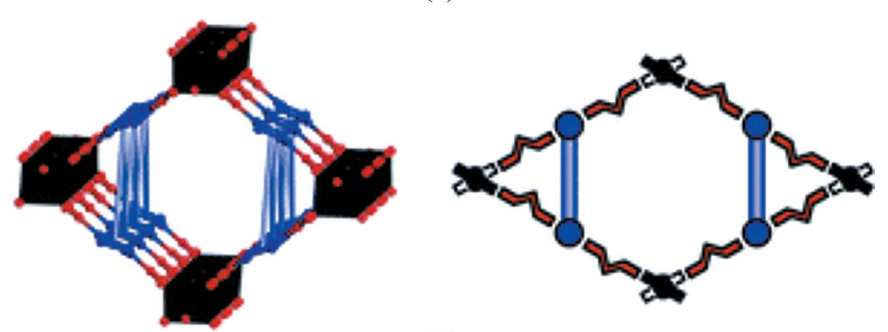

(b)

Figure 5

Schematic representations of XBUs in two-dimensional MOF analogues taken from Ogborn et al. (2012). (a) MOF-5, like $\mathrm{Zn}(\mathrm{CN})_{2}$, consists of a connected array of 'strut' XBUs and (b) MIL-53, like $\mathrm{Ag}_{3}\left[\mathrm{Co}(\mathrm{CN})_{6}\right]$, is represented as an array of connected hinge XBUs with very soft additional interactions. Reprinted from Ogborn et al. (2012). Copyright (2012) Royal Society of Chemistry. sibility (PLC) above $1.5 \mathrm{GPa}$ (Ogborn et al., 2012). This direction also exhibits NTE behaviour and the effects are comparable in scale to the 'colossal' responses in $\mathrm{Ag}_{3}\left[\mathrm{Co}(\mathrm{CN})_{6}\right]$ discussed above. Ogborn et al. ascribe the cause of the NLC to mechanical responses of the so-called mechanical building units (XBUs, Fig. 5): chains of $\mathrm{Ag}^{+} \cdots \mathrm{Ag}^{+}$ interactions parallel to the $a$-axis; these argentophilic chains acting as spindles in Ag-MeIM-Ag hinges; and struts composed of the MeIM linkers (Ogborn et al., 2012). Competition between flexing of the hinge angle $(\theta$, which decreases as the $c$-axis increases) and strut length ( $r$, which decreases as the $c$-axis decreases) is said to dictate the compressibility, with the former dominating at lower pressures (hence NLC), and the latter dominating at higher pressures (hence PLC). The deconvolution of the MOF to XBUs is an extension of the wine-rack analogy and similar to the 'nodes and spacers' description of MOFs, where secondary building units (SBUs; Kim et al., 2001) or molecular building units (MBUs; Yaghi \& Li, 1996) are used to describe them. However, the XBU description does allow for some general rules regarding anisotropic mechanical responses induced by temperature or pressure. For instance, as a general rule for MOFs, the authors note that strong NLC is most likely to occur when hinges are as flexible as possible (i.e. a large $K_{\theta}$ ) but are connected via strong inflexible struts (i.e. small $K_{\mathrm{r}}$; Ogborn et al., 2012).

In the context of mechanical properties, MOFs are often described as being either compliant (flexible) or noncompliant (rigid), the degree to which one can describe a MOF as flexible has indeed caused some debate in the field. In a similar vein to the XBU deconvolution of MOFs, Ortiz et al. (2013) described an ab initio computational approach to analysing elastic constants in a series of MIL frameworks, enabling some further general observations on the relationship between geometric shape and flexibility. In a compliant wine-rack such as MIL-53, each vertex of the wine-rack is a metal centre hinge and the framework is likely to display a highly anisotropic Young's modulus, shear modulus and Poisson's ratio, and at least one direction of NLC (Fig. 6). By contrast, in MIL-122 $\left[M_{2}\left(\mathrm{OH}_{2}\right)\left(\mathrm{C}_{14} \mathrm{H}_{4} \mathrm{O}_{8}\right)\right.$; Volkringer et al.,
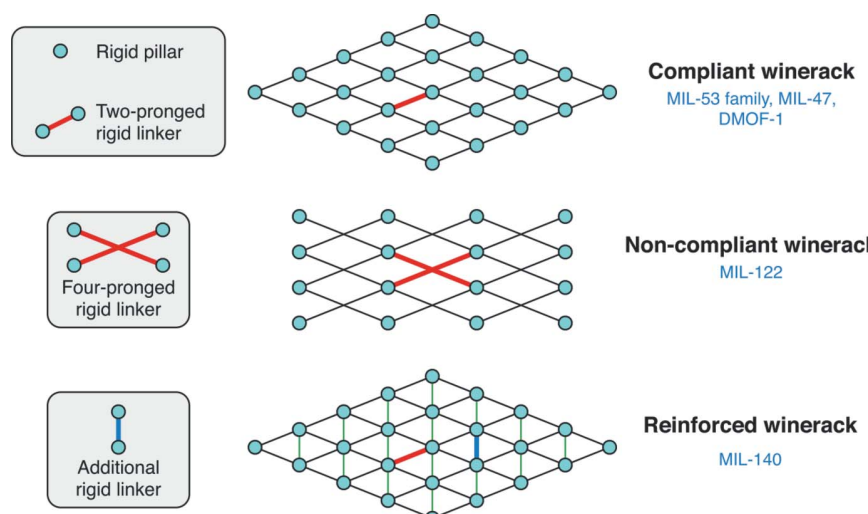

Non-compliant winerack MIL-122

Figure 6

Sketch of the three families of MOFs exhibiting wine-rack motifs showing decreasing degrees of 'flexibility'. Reprinted from Ortiz et al. (2013). Copyright (2013) AIP Publishing. 
2009], half of the vertices in the wine-rack are at the centre of the four-pronged 1,4,5,8-naphthalenetetracarboxylate linker and therefore cannot act as hinges. MIL-122 is therefore a non-compliant wine-rack in which the scope for highly elastic behaviour is diminished. The authors also identify a third framework type - the reinforced wine-rack - which has an additional organic ligand in place of the hydroxide bridge in MIL-53 and thus an additional, vertical strut between adjacent hinges (Fig. 6). This structure is exemplified by the MIL-140 family of Zr- and dicarboxylate-based frameworks (Guillerm et al., 2012). The additional component directly affects the ability of the hinges to 'open' and thus linear compressibility is positive in all directions.

The work on $\operatorname{Ag}(\mathrm{MeIM})$ (Ogborn et al., 2012) is complemented by that of Li et al. (2012) who, using nanoindentation, found that the $c$-axis direction (corresponding to the onedimensional channel direction) of the hexagonal $\left[\mathrm{NH}_{4}\right]\left[\mathrm{Zn}(\mathrm{HCOO})_{3}\right]$ (Wang et al., 2007) framework was significantly less compressible $[E=34.4$ (9) GPa] than the $a / b$ directions $[E=18.2(2) \mathrm{GPa}$ ]. This was confirmed using highpressure XRD experiments which showed that the linear compressibility of the $a / b$ axes is $15.8(9) \mathrm{TPa}^{-1}$ while the $c$ axis displays a NLC of $-1.8(8) \mathrm{TPa}^{-1}$ from 0 to $1 \mathrm{GPa}$. The diffraction data, in combination with density functional theory (DFT) calculations, showed that this NLC corresponds to a shortening of the $\mathrm{Zn}-\mathrm{O}$ bonds with a simultaneous tilting of the rigid formate ligands as pressure is increased. This combination increases the $\mathrm{Zn}-\mathrm{Zn}-\mathrm{Zn}$ hinge angle $(\theta)$ facing the $c$-axis, thus increasing its length (i.e. along the direction of the one-dimensional channel) while the $a / b$ axes contract.

Although the work by Ogborn et al. (2012) and Li et al. (2012) emphasizes the importance of a rigid organic strut in promoting NLC, it is instead the flexible nature of the organic linker which promotes NLC in ZAG-4 and ZAG-6. These MOFs are comprised of $\mathrm{Zn}-\mathrm{O}-\mathrm{P}-\mathrm{O}$ eight-membered rings fused through zinc into a one-dimensional chain which is hydrogen bonded in one direction (approximately along $b$ ) to neighbouring chains and cross-linked in the other direction (approximately along $a$ ) by a butane linker in ZAG-4, and a hexane linker in ZAG-6. The narrow hydrogen-bonded channel runs along the $c$-axis and is filled with water molecules, rendering the structure effectively non-porous (Fu et al., 2003; Gagnon et al., 2012). Clearfield and co-workers (Gagnon et al., 2013) report a large bulk modulus (11.7 GPa) for ZAG4, which is reversibly compressible up to $9.9 \mathrm{GPa}$. Remarkably, there was no amorphization or decline in the single-crystal quality over the course of the high-pressure XRD experiments. Upon release of pressure, the crystal volume returned to its ambient value. A large compression is observed in the $a$ axis over the course of the pressure regime (a contraction of $17 \%$ ) by virtue of the ligand flexibility. While the vast majority of MOFs contain rigid (usually aromatic) linkers, ZAG-4 is connected by comparably more flexible alkyl chains which act as spring-like cushions. This permits large distortions in the metal coordination environment - the $\mathrm{O}-\mathrm{Zn}-\mathrm{O}$ angle opens and reduces the $\mathrm{Zn}-\mathrm{Zn}$ bond length from 4.245 (1) to 3.754 (1) $\AA$ - which accounts for a $10 \%$ decrease in the length of the $c$-axis up to $9.9 \mathrm{GPa}$. The $b$-axis by contrast exhibits PLC from 0 to $1.65 \mathrm{GPa}$ followed by a continuous NLC above this pressure. Although the exact cause of this behaviour is unclear, the authors attribute it to the initial compression of the inorganic chains and hydrogen-bonded channels along $b$, which then 'push back' as the collective force of the watermediated hydrogen bonding strengthens and the inorganic chain expands (Gagnon et al., 2013). This anomalous behaviour is interesting to speculate over, since the motifs governing the mechanical response are in contrast to the previous examples. We would also suggest that it appears to be a 'secondary' response, i.e. one which results from the compression of the linkers in an orthogonal direction and the presence of water in the channels, rather than an intrinsic structural effect as observed in the other examples ( $\mathrm{Li}$ et al., 2012; Ogborn et al., 2012). In ZAG-6, less dramatic NLC behaviour is observed, with an overall increase in length of $2 \%$ observed along the $b$-axis direction. More strikingly, however, is that the NLC behaviour in ZAG-6 is also accompanied by a pressure induced 'coiling' of the hexane chain, quantified by a large reduction of the $\mathrm{C}-\mathrm{C}-\mathrm{C}-\mathrm{C}$ torsion angles, reducing in the most extreme case from 173.7 (3) to $55.3(10)^{\circ}$, and corresponds to a novel piezo-mechanical response of a flexible MOF to pressure. This transition does not occur in the shorter butanediphosphonate linker. Notably, the transition also causes a proton transfer from the phosphonate group to a water molecule which resides within the channels. The authors discovered that the proton transfer is in fact stabilized by the increase in pressure, which permits the phosphonate and water molecule to move closer together, minimizing the $P V$ contribution to the enthalpy.

\section{Guest-dependent high-pressure phenomena}

Until this point, we have focused our discussion mostly on high-pressure behaviour which is largely independent of the liquid used to apply hydrostatic pressure in high-pressure XRD experiments. The remainder of this review shall discuss structural effects which are, to one extent or another, dependent on the liquid used. There have also been many complementary mechanical and computational studies performed on some well known MOFs (e.g. MOF-5, ZIF-8, HKUST-1), so these shall also be discussed alongside the medium-dependent crystallographic work. Most high-pressure MOF studies fall into this category, which by its nature is much broader. Although most porous MOFs have guest molecules from the original synthesis residing in the framework, the word 'guest' in high-pressure crystallographic work tends to be used interchangeably with that of the hydrostatic liquid used in the subsequent experiments. Since the MOF pores are filled with the liquid when a penetrating medium is used, the molecules of the liquid essentially become the guests in a displacive process.

From our literature search we found two notable exceptions to this rule, both in publications by Ross and co-workers. The first study (Spencer et al., 2012) concerns the three-dimensional copper carbonate MOF, $\left[\mathrm{Cu}\left(\mathrm{CO}_{3}\right)_{2}\right]\left(\mathrm{CH}_{6} \mathrm{~N}_{3}\right)_{2}$ (Abra- 
hams et al., 2003), which has an anionic $\left[\left(\mathrm{Cu}\left(\mathrm{CO}_{3}\right)_{2}\right)^{2-}\right]_{n}$ framework with a diamond-like topology in which the tetrahedral nodes of the diamond are replaced by $\mathrm{Cu}^{\mathrm{II}}$ ions in square-planar coordination environments. Charge-balancing guanidinum cations occupy the framework pores and block the porosity. The guest is well ordered as a result of strong, clearly defined hydrogen bonding with the framework, which has a mechanically stabilizing effect on the structure. Crucially, the guest ions are not displaced by small alcohols used as hydrostatic media in high-pressure XRD experiments. The authors report a massive bulk modulus for this material [36.1 (3) $\mathrm{GPa}$ as well as elastic properties which demonstrate a structural strength comparable to zeolites. The second study (Spencer et al., 2013) in which the guest molecule plays a pivotal role in the high-pressure behaviour concerns $\mathrm{Tb}$ GWMOF6 (de Lill et al., 2007), a three-dimensional framework containing $\mathrm{Tb}^{3+}$ ions linked by hexane-1,6-dicarboxylate ligands. The material exhibits interesting optical properties as a direct result of unprotonated bipy molecules residing in the framework cavities which enhance the intensity of the photoluminescence emission of the $\mathrm{Tb}^{3+}$ centres. Three pressure-induced phase transitions are reported for this MOF over the $0-4$ GPa range, with significant changes in the ${ }^{5} \mathrm{D}_{4} \rightarrow{ }^{7} \mathrm{~F}_{5}$ emission spectra. The authors were unable to solve the highpressure crystal structures of Tb-GWMOF6 and it is also unspecified whether the methanol:ethanol hydrostatic liquid acts as a penetrating or non-penetrating medium, i.e. by displacing the bipy guest molecules. However, we assume from the interesting high-pressure luminescence results that the bipy molecules remain in the framework cavities and that the high-pressure behaviour is therefore guest- and not mediumdependent.

The remainder of this section will discuss crystallographic work which is hydrostatic medium-dependent alongside relevant mechanical and computational studies. We will first discuss in their own section the work performed on ZIFs which are, for reasons outlined in \$2.1, the family of MOFs most intensively studied for their high-pressure and related mechanical properties.

\subsection{Zeolitic imidazolate frameworks}

4.1.1. Mechanical properties. In addition to the dense ZIFzni framework as discussed in \$2.1, Tan et al. (2010) also determined the elastic modulus and hardness properties of six porous ZIFs by means of single-crystal nanoindentation. A broad range of network topologies and porosities is represented by their choice of ZIF-4 $\left[\mathrm{Zn}(\operatorname{Im})_{2}\right.$ with cag network topology (O'Keeffe et al., 2008)], ZIF-7 [Zn(bIm) $)_{2}$; bIm = 2benzimidazolate], ZIF-8, ZIF-9 [Co(bIm) $)_{2}$, ZIF-20 [Zn(pur) $)_{2}$; pur $=$ purine $]$ and ZIF-68 [Zn(bIm) $(\mathrm{nIm}) ; \mathrm{nIm}=2$-nitroimidazolate]. Although it does not provide structural insight into the effect of pressure on the ZIF family, the study clearly defined the inversely correlated relationship between the elastic modulus and accessible void space, i.e. as a general rule, a framework's elasticity (compliance) increases with its porosity. The same is also true of the framework hardness, where low density/high porosity frameworks such as ZIF-8, ZIF-20 and ZIF-68 are relatively soft phases, with hardness values lying in the range 200-500 MPa, compared with the denser ZIF-7 and ZIF-9 (where $H=650-700 \mathrm{MPa}$ ). Notably the sterically larger bIm groups in ZIF-7 and ZIF-9 increase the pressure of amorphization (Zhao et al., 2015). These properties are often related to the nature of the organic linker. ZIFs of the same topology with sterically bulkier, highly aromatic, ligands are often harder with greater stiffness due to short-range ligand-ligand interactions (Tan \& Cheetham, 2011). These nanoindentation experiments by Tan et al. (2010) also showed that when DMF molecules were evacuated from the pores of ZIF-8, a decrease in elastic modulus occurs, but upon subsequent exposure to DMF the original framework stiffness recovers. This use of mechanical properties to demonstrate the guest-dependent dynamic behaviour of MOFs illustrates this key concept relevant to high-pressure behaviour. The mechanical stability of ZIFs has also been investigated in an extensive computational study on ZIFs by Bouëssel du Bourg et al. (2014), where the application of hydrostatic pressure (maximum applied being $1.5 \mathrm{GPa}$ ) to ten different ZIF frameworks with $A F I, C A N$, cag, coi, DFT, $F A U, L T L, M E R, n o g$ and $S O D$ topologies, revealed that the ZIFs showed relatively low stability on compression, with the coi framework (which is among the most dense studied), showing the greatest resistance to compression (Bouëssel du Bourg et al., 2014).

4.1.2. High-pressure crystallography and molecular modelling. The mechanical changes in ZIF-8 in response to adsorption/desorption of DMF (Tan et al., 2010) also highlight a much-studied feature of ZIFs: reversible guest uptake. In particular, ZIF-8 combines the desired properties of a large and permanent porosity (solvent accessible volume $\simeq 50.4 \%$ ) and extreme hydrothermal stability (Low et al., 2009). This framework and others with high porosity/stability are noted for their gas storage potential (Banerjee et al., 2008). The most intriguing aspect of gas uptake in ZIFs is the gating phenomenon, which is similar to the breathing mechanism in MIL-53. This phenomenon is reflected by a step in the adsorption isotherm of, for example, $\mathrm{N}_{2}$ adsorption by ZIF-8 at 0.02 bar and $77 \mathrm{~K}$ (Fairen-Jimenez et al., 2011), or $\mathrm{CO}_{2}$ adsorption by ZIF-7 at 0.6 bar and $303 \mathrm{~K}$ (Aguado et al., 2011), which is accompanied by a sudden and rapid increase in guest uptake. Such sigmoidal-shaped (type IV) isotherms typically correspond to changes in the local pore structure. Using highpressure single-crystal X-ray diffraction, Moggach and coworkers (Moggach, Bennett et al., 2009) were the first to report the structural changes causing this effect, exemplified using ZIF-8. ZIF-8 under ambient conditions contains one nanosized pore $(V=2465 \AA)$ connected by eight smaller channels containing some residual post-synthesis solvent. A crystal was loaded in a DAC with a 4:1 (volume ratio) mixture of methanol and ethanol as a hydrostatic medium. As pressure was increased step-wise, diffraction data revealed a gradual filling of the framework pores, from 219 electrons per unit cell at ambient pressure to 421 electrons at $0.96 \mathrm{GPa}$. This was calculated using the PLATON SQUEEZE algorithm (Spek, 
2009) since the disorder of the guest molecules prohibited them from being modelled crystallographically. These numbers correspond to approximately 12 molecules of methanol per unit cell at ambient pressure and 23 molecules at $0.96 \mathrm{GPa}$. There was also a corresponding initial increase in the unit-cell volume as pressure was increased, from $4900.5(8) \AA^{3}$ at ambient pressure to $4999.6(2) \AA^{3}$ at $0.18 \mathrm{GPa}$, followed by a steady decrease in volume up until $0.96 \mathrm{GPa}$. When pressure was then increased to $1.47 \mathrm{GPa}$, a SC-SC transition occurred, whereby the MeIm linkers twist by $\sim 25^{\circ}$ through the two $\mathrm{N}$ atoms which act as hinges (Fig. 7). This has the effect of allowing more solvent into the framework as the size of the channels increase, causing an increase in both the unit-cell volume [now $4974.8(9) \AA^{3}$ ] and the residual electron count (equivalent to 41 methanol molecules per unit cell) on undergoing the transition. This gating effect is fully reversible, both in ZIF adsorption/desorption isotherms and in the ZIF-8 crystal structure (Moggach, Bennett et al., 2009).

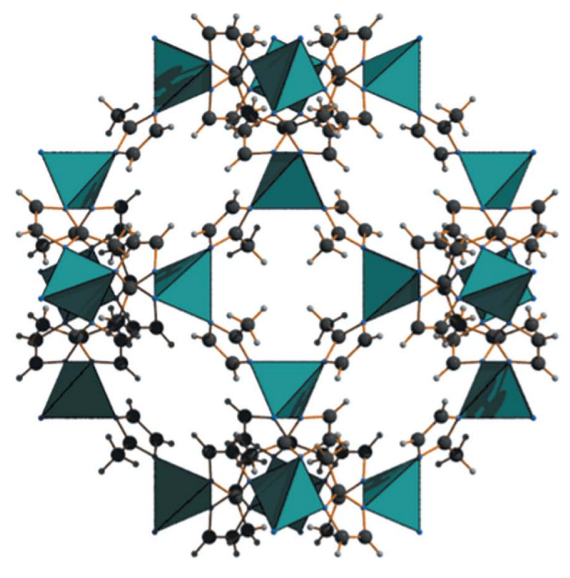

(a)

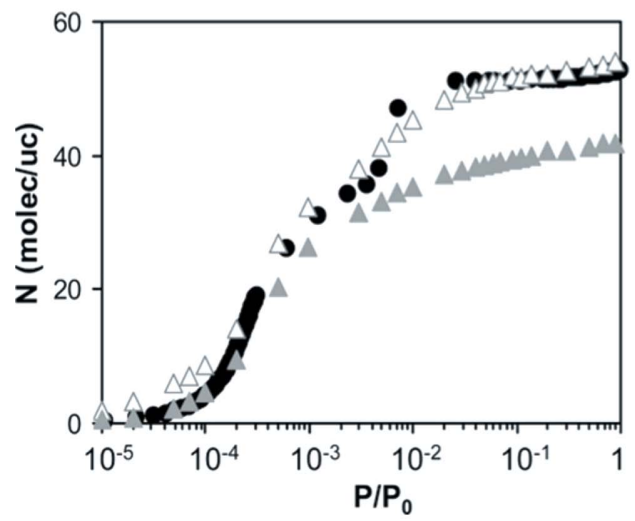

(c)

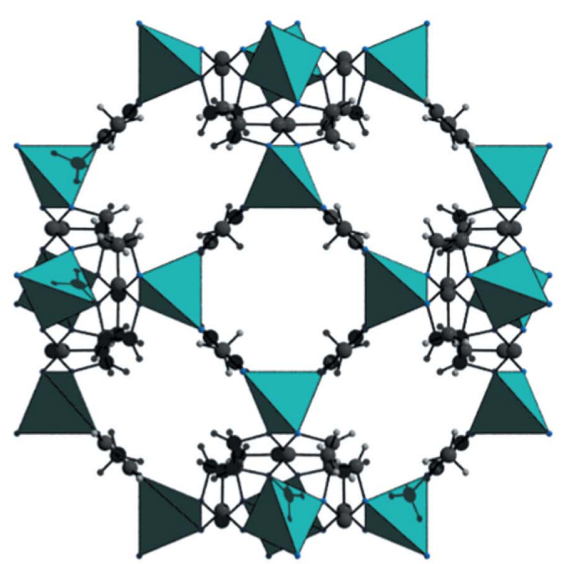

(b)

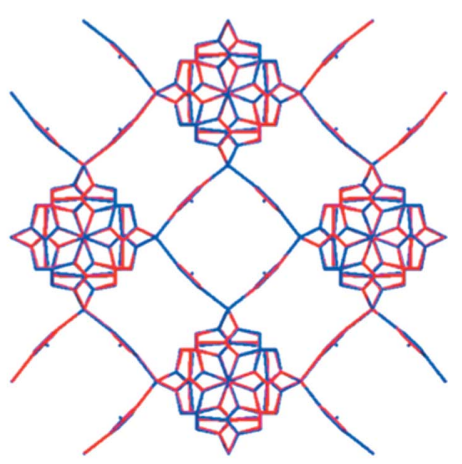

(d)
Figure 7

Packing arrangement of ZIF-8 at $(a)$ ambient pressure and $(b)$ at $1.47 \mathrm{GPa}$. $\mathrm{ZnN}_{4}$ tetrahedra are represented as solid green polyhedra (image adapted from Moggach et al., 2009). Colour key: C, dark grey; $\mathrm{H}$, light grey. (c) Semilog plot of $\mathrm{N}_{2}$ adsorption on ZIF-8 at $77 \mathrm{~K}$ : experimental, circles; and simulated data on ambient pressure structure, ZIF-8, closed triangles and high-pressure structure, ZIF8HP, open triangles. Reprinted from Fairen-Jimenez et al. (2011). Copyright (2011) American Chemical Society. (d) Overlay of ZIF-8 loaded with $\mathrm{N}_{2}$ (blue) and the 1.47 GPa structure determined by Moggach et al. (2009) (red). Reprinted from Fairen-Jimenez et al. (2011. Copyright (2011) American Chemical Society.
This work is an effective demonstration of how high-pressure XRD experiments can pinpoint flexibility within a framework, but follow-on work by Fairen-Jimenez et al. (2011) has also shown how such results can be used complementarily to molecular simulations. For gas adsorption applications of MOFs, molecular simulations are important since they offer insight into gas adsorption sites and diffusivity. Such approaches are becoming more and more commonplace (Yang et al., 2013), but theoretical models have in the past been complicated by framework flexibility which can cause discrepancies between predicted (Haldoupis et al., 2010) and experimental (Bux et al., 2009, 2010) data. ZIF-8, for instance, has narrow 6ing windows $(\sim 3.4 \AA$ opening), in theory suitable for eparation of hydrogen (kinetic diameter $\simeq 2.9 \AA$ ) from larger methane $(\sim 3.8 \mathrm{~A})$ and nitrogen $\left(\mathrm{N}_{2}\right.$; A), if the framework is assumed to be rigid (Fairenet al., 2011). However, larger molecules including $\mathrm{N}_{2}$ and hydrocarbons can be adsorbed (Zhou et al., 2007; Huang, Lin et al., 2006; Luebbers et al., 2010) due to the gating mechanism and the corresponding increase in the window size. Until the elucidation of the high-pressure ZIF-8 structure (Moggach, Bennett \& Cheetham, 2009), there was no such structural explanation for this behaviour. One of the most interesting aspects of this high-pressure work is that the structural changes at $1.47 \mathrm{GPa}$ were used by FairenJimenez et al. (2011) to model the ambient-pressure gating mode responsible for the increased $\mathrm{N}_{2}$ uptake (Figs. $7 c$ and $d$ ). One pertinent question for future work on this system is why, in liquid methanol:ethanol, GPa pressures are required to obtain the 'open' framework structure while in gaseous $\mathrm{N}_{2}$, the same structure is obtainable at less than $1 \mathrm{~atm}$ ? Of course, the chemical nature of the guest dictates the framework-guest interactions which must play a pivotal role in causing the twisting of the ligands. A recent report of ZIF-8 using high-pressure Fourier transform-IR (FT-IR) spectroscopy indicates that reversible guest storage behaviour is also observed using solid $\mathrm{CO}_{2}$ up to 2.65 GPa (Hu et al., 2011). In the absence of structural data, it is unknown if this also causes a rotation of the MeIm ligands. Although there is no step in the $\mathrm{CO}_{2}$ adsorption isotherm (Aguado et al., 2011), recent work has also shown 
for methane that this may not always be indicative of the transition taking place (Fairen-Jimenez et al., 2012). As to the question of the differences of gating pressure in methanol:ethanol and in $\mathrm{N}_{2}$, clearly in the high-pressure phase of ZIF-8 there is a critical pressure, or critical density of methanol:ethanol within the pore, that overcomes the free energy barrier to the twisting of the MeIM rings. The story is even more complicated in ZIF-8, as the pressure at which the gating mechanism occurs has even been seen to be crystallite sizedependent (Zhang et al., 2014). This has been addressed somewhat by Zhao et al. (2014) who considered ZIF-7 which, unlike ZIF-8, does exhibit gate-opening behaviour on exposure to $\mathrm{CO}_{2}$ (van den Bergh et al., 2011; Morris et al., 2012) due to rotation of the bIm linkers (Aguado et al., 2011). The authors found that the bIm rotation is exquisitely sensitive to the $\mathrm{CO}_{2}$ gas pressure. From 1 to 2 bar, the external pressure drives direct compression of the two crystallographically distinct framework cavities, which are bridged by the bIm linkers. However, the degree of the rotation here is actually less than that observed at 0.6 bar, when the gas flows freely from one cavity to the other and bIm rings rotate to increase the size of the voids so that more $\mathrm{CO}_{2}$ molecules can enter. Thus, the adsorption properties of ZIF-7 depend upon a balance between the internal pressure of the guest molecule in the cavities and the external gas pressure (Zhao et al., 2014). Perhaps there is a similar effect occurring in ZIF-8, where even upon initial loading in the DAC with methanol:ethanol, there is an extremely high pressure both inside and outside the framework, compared with a much lower external pressure in the $\mathrm{N}_{2}$ system. In any case, the high-pressure crystal structure of ZIF-8 has enabled researchers to understand the structural mechanism causing the step in the adsorption isotherm and has since been exploited in $\mathrm{CO}_{2}$ and hydrocarbon gas separation processes (Gücüyener et al., 2010; Nijem et al., 2012; Zheng et al., 2013; Peralta et al., 2012) which include industrial patent applications by ExxonMobil (Deckman, Kortunov, Ni, Paur, Reyes et al., 2015; Deckman, Kortunov, Ni, Paur, Zengel et al., 2015).

\subsection{The effect of solvent inclusion on compressibility}

4.2.1. MOF-5. The SC-SC phase change in ZIF-8 is a result of superfilling (or hyperfilling) with a penetrating medium. This is a common phenomenon in porous MOFs and involves progressive filling of accessible pore volume by smaller guest molecules, often inducing a transition between two compression regimes following saturation of the framework. The effect of superfilling on the compressibility of a framework is profound and has been investigated extensively by our group and collaborators. A good example is that of MOF-5, where Graham et al. (2011) calculated the bulk modulus of the evacuated framework to be $16.5 \mathrm{GPa}-$ a result which is in good agreement with previous studies $(K=16.3-18.5 \mathrm{GPa}$; Zhou \& Yildirim, 2006; Mattesini et al., 2006; Samanta et al., 2006; Bahr et al., 2007). In their complementary high-pressure XRD study from the same paper, single-crystal XRD data were collected on MOF-5 up to $3.2 \mathrm{GPa}$ with diethyl forma- mide (DEF) as a hydrostatic medium. In this case, the superfilling of the crystal with DEF molecules massively increased the bulk modulus, which was estimated to be $242 \mathrm{GPa}$ (over the $0.1-0.7 \mathrm{GPa}$ pressure range) and 20$40 \mathrm{GPa}$ at higher pressures.

The effect of guest content here highlights one source of difficulty encountered when calculating mechanical properties in MOFs. Other problems are observed for MOF-5 in particular, which has been the subject of several computational attempts to characterize its elastic properties and compressibility. These have been comprehensively reviewed by Tan \& Cheetham (2011). In short, two general observations regarding discrepancies in this work can be made. Firstly, finite-temperature molecular dynamics (MD) simulations in one report show a $14 \%$ decrease in the bulk modulus of MOF5 (from 19.4 to $16.7 \mathrm{GPa}$ ) over a simulation temperature range of 10-300 K (Han \& Goddard, 2007), while in another the drop is closer to $25 \%$ (Tafipolsky \& Schmid, 2009). Secondly, there are often discrepancies between predicted and experimental data. Using single-crystal nanoindentation on MOF-5, Bahr and co-workers (Bahr et al., 2007) measured the elastic modulus along the principal axis directions to be $7.9 \mathrm{GPa}$, while their DFT calculations estimated this to be almost three times greater $\left[E_{(100)}=21.6 \mathrm{GPa}\right.$ at $\left.0 \mathrm{~K}\right]$. The use of force fields in MD simulations often predict even higher stiffness $\left[E_{(100)} \simeq\right.$ 31-42 GPa when $300>T>10 \mathrm{~K}$ in one study (Han \& Goddard, 2007) and $E_{(100)} \simeq 14.9-35.5 \mathrm{GPa}$ when $300>T>$ $10 \mathrm{~K}$ in another (Greathouse \& Allendorf, 2008)]. Tan and Cheetham note that from a computational point of view, MD simulations can be sensitive to the choice of force field. From an experimental perspective, they ascribe discrepancies with the predicted data partly to the degradation of the crystals. MOF-5 is known to decompose on exposure to air and humidity (Kaye et al., 2007; Low et al., 2009), yielding crystals with much lower stiffness than in the idealized structure used in the calculations. These discrepancies observed in MOF-5 overlap somewhat with the previous discussion of ZIF-8, which demonstrated that flexibility in a framework can complicate theoretical models. In some respects the opposite effect is observed in the high-pressure behaviour of MOF-5: in their study of the lattice dynamics, Zhou \& Yildirim (2006) and others (Biswas \& Cagin, 2011) note that the framework is close to structural instability and that a structural transformation could be induced under high pressure. They identified the low energy barrier to rotation for the BDC aromatic ring around its long axis as the most likely site for such a transformation.

However, in the high-pressure XRD experiment of MOF-5 using DEF as a hydrostatic liquid (referred to as MOF-5DEF; Graham et al., 2011), no such transformation was observed. Instead, the compression is mediated more subtly through the metal-ligand bonds, which by their nature are much more amenable to pressure modification (Moggach, Galloway et al., 2009) than covalent bonds (Moggach, Parsons \& Wood, 2008). There are two symmetry-independent $\mathrm{Zn}-\mathrm{O}$ bonds in MOF-5 (Fig. 8). These are from each $\mathrm{Zn}$ atom to a $\mu^{4}$-oxygen atom (O1), which sits at the centre of the $\mathrm{Zn}_{4} \mathrm{O}_{13}$ cluster, and a 
carboxyl oxygen atom $(\mathrm{O} 2)$. Over the course of the experiment, three behaviourally distinct pressure regions could be identified. Initially, from $0.33-0.78 \mathrm{GPa}$, the framework continually expands as it is superfilled with DEF. In the second region $(0.78-2.01 \mathrm{GPa})$, there is a sudden drop in the pore content as the framework then begins to compress, squeezing the liquid back out of the pores. From 2.01 to $3.24 \mathrm{GPa}$, there is a sharper drop in the unit-cell volume and steady compression of the framework. Little change was observed in the length of the $\mathrm{Zn}-\mathrm{O} 1$ bond over the entire pressure series, while the length of $\mathrm{Zn}-\mathrm{O} 2$ contracts by almost $1 \AA$ between 0.30 and $2.35 \mathrm{GPa}$. The most pronounced contraction occurs, as would be expected, above the pressure at which the initial rapid evacuation of the pores is observed. Graham et al. (2011) note that the greater compressibility of $\mathrm{Zn}-\mathrm{O} 2$ lends experimental proof to a previous ab initio study showing that $\mathrm{O} 1$ has a greater negative charge than $\mathrm{O} 2$ by around $-0.4 \mathrm{e}^{-}$ (Zhou \& Yildirim, 2006) and that the $\mathrm{Zn}-\mathrm{O} 2$ bond is formed by charge donation from the $\mathrm{O}$ atom. Interestingly, DFT calculations indicate that the compressibility of $\mathrm{Zn}-\mathrm{O} 1$ and $\mathrm{Zn}-\mathrm{O} 2$ in a guest-free MOF-5 (referred to as MOF-5Evac) are much more similar, which suggests that the inclusion of solvent in the pores makes the $\mathrm{Zn}-\mathrm{O} 1$ bond stiffer (Fig. 8).

One other intuitive point which is obvious from this work and relevant to all high-pressure MOF studies is that the use of a penetrating hydrostatic medium will stabilize a MOF during the onset of extreme external pressure. Pressure-induced amorphization (Chapman et al., 2009) is common in MOF
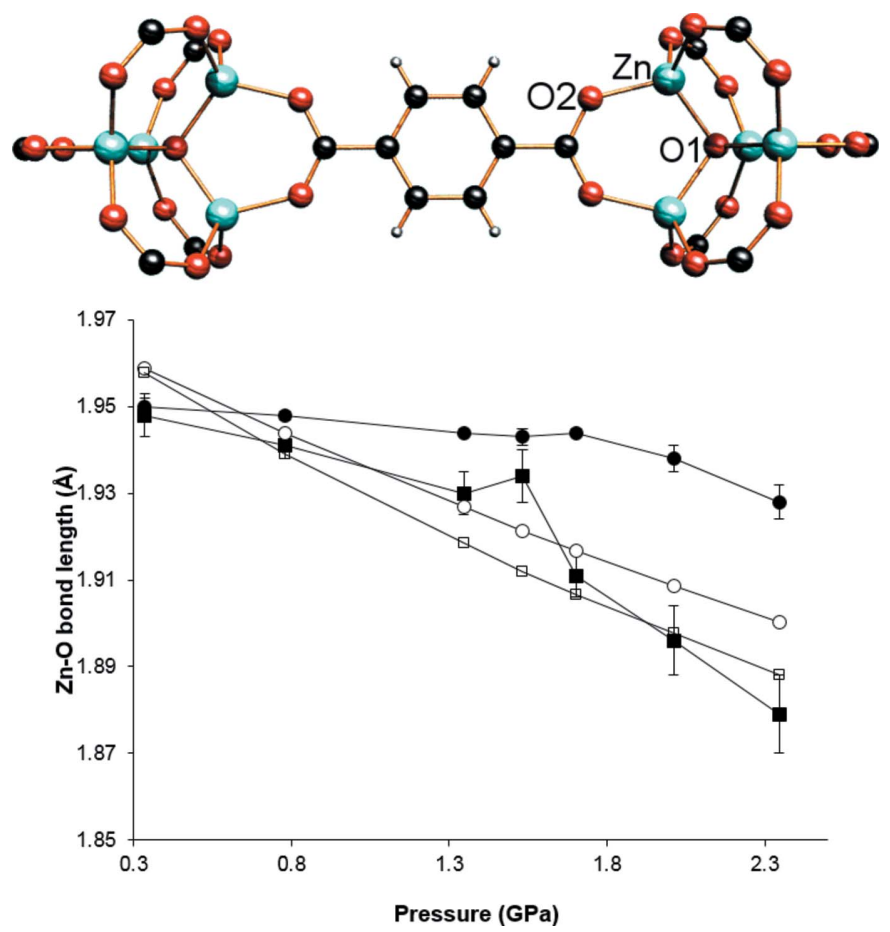

Figure 8

Variation in $\mathrm{Zn}-\mathrm{O} 1$ (circles, $\mu^{4}$-oxygen atom) and $\mathrm{Zn}-\mathrm{O} 2$ (squares, carboxyl oxygen atom) bond lengths in MOF-5DEF and MOF-5Evac (derived from the computational analysis) as a function of pressure. Filled and empty data points refer to MOF-5DEF and MOF5-5Evac, respectively. Figure adapted from Graham et al. (2011). materials - particularly with a non-penetrating medium, which has no such stabilizing effect - and will be discussed in more detail in $\S 5$. It is worthy of brief mention here since it is also relevant to superfilling behaviour. Amorphization has previously been induced in MOF-5 via grinding (Hu \& Zhang, 2010). Although amorphization of MOF-5 in DEF was eventually observed by Graham et al. (2011), it was at pressures several orders of magnitude higher than those achievable in grinding experiments.

4.2.2. HKUST-1. The high-pressure pore-filling mechanism described for MOF-5 corresponds well with earlier highpressure powder XRD experiments on HKUST-1 by Chapman et al. (2008) who used MEW, IPA and FC-70 as separate hydrostatic media. This was the first study to demonstrate that the compressibility of a nanoporous MOF is strongly dependent on the type of pressure-transmitting liquid used. In MEW and IPA, a dramatic transition between two regions of near-linear compressibility was observed. The change between the 'hard' regime $(K \simeq 118 \mathrm{GPa})$ and 'soft' regime ( $K \simeq 30 \mathrm{GPa})$ was ascribed to the change between a hyperfilling and a pore-emptying mechanism. In contrast, in non-penetrating FC-70, direct compression of the framework occurred and the sample became amorphous at significantly lower pressure than with the penetrating media. However, since no structural data were reported, high-pressure singlecrystal diffraction experiments conducted by Graham et al. (2012) were able to elucidate the exact nature of the structural transition between the hard and soft regimes using MEW as a pressure-transmitting liquid. It was confirmed that pore-filling of the framework continued from 0 to $3.9 \mathrm{GPa}$, which is in good agreement with the work by Chapman et al. (2008). Above this pressure, the unit-cell volume decreases suddenly and markedly [from 17948.3 (30) to $17468.1(20) \AA^{3}$ ], as does the total pore volume (from 11445 to $10996 \AA^{3}$ ). The corresponding pore content does not decrease significantly (by $\sim 16 \%$ ) and is roughly the same at $5.0 \mathrm{GPa}$ as that observed at 3.0 GPa, while the unit-cell volume is $632 \AA^{3}$ lower at $5.0 \mathrm{GPa}$ than at 3.0 GPa. Therefore, the driving force for the reduction in volume is not just the reduction in pore content. Like the behaviour of MOF-5, the authors note significant changes in the $\mathrm{Cu}-\mathrm{O}$ bonds. There are two unique $\mathrm{Cu}-\mathrm{O}$ bonds in HKUST-1: an equatorial $\mathrm{Cu}-$ carboxylate bond $(\mathrm{Cu}-\mathrm{O} 1)$ and an axial $\mathrm{Cu}$-water bond $(\mathrm{Cu}-\mathrm{O} 2)$, the latter pointing into the pores. Above $3.9 \mathrm{GPa}$, the $\mathrm{Cu}-\mathrm{O} 2$ bond length suddenly increases after a steady contraction, while the $\mathrm{Cu}-\mathrm{O} 1$ bond contracts by a similar degree after remaining largely unchanged over the course of the pressure regime. The authors note that the transition at higher pressure is therefore driven by the sudden compression of the significantly stiffer equatorial $\mathrm{Cu}-\mathrm{O} 1$ bonds which causes the axial $\mathrm{Cu}-\mathrm{O} 2$ bond to increase in length on undergoing the transition, and the transition here is driven by the need to minimize the volume of the system at $5.0 \mathrm{GPa}$.

4.2.3. $\mathrm{Sc}_{2} \mathrm{BDC}_{3}$.

(i) Preferential adsorption and the role of guest-guest interactions in the superfilling of $\mathbf{S c}_{2} \mathbf{B D C}_{\mathbf{3}}$ : We recently performed a detailed study on the stabilization of a MOF by 
superfilling using the scandium terephthalate $\mathrm{MOF}, \mathrm{Sc}_{2} \mathrm{BDC}_{3}$. $\mathrm{Sc}_{2} \mathrm{BDC}_{3}$ (Miller et al., 2005) has very high chemical and thermal stability and is composed of $\mathrm{ScO}_{6}$ octahedra and BDC ligands and crystallizes in the orthorhombic space group $F d d d$ under ambient conditions. It is similar to MIL-53 in its structure, except that the hydroxide bridge in MIL-53 is replaced by an extra BDC molecule which essentially splits the rhomboidal channel openings into small triangular prism-shaped channels with a free diameter of $\sim 4 \AA$ (Fig. 9a). The channels are hydrophobic in nature and thus devoid of solvent or water post-synthesis. At room temperature there are two crystallographically unique BDC species designated as Group 1 and 2 and identified in Fig. 9(a). Although the channels (which run along the $a$-axis direction) appear one-dimensional, there are small gaps in the channel walls between adjacent BDC ligands, giving rise to three-dimensional porosity in both the $b$ and $c$ axis directions. Previous reports have shown that this narrow channel and constrained pore system in the other two dimensions provides well defined preferential gas adsorption sites (Miller et al., 2009; Mowat et al., 2011).

Upon compression in methanol in our high-pressure singlecrystal XRD study, methanol was found to enter the framework, despite its internal hydrophobic environment, and occupy two distinct sites with no change to the crystal symmetry. Site 1 is located on either side of the gaps created by Group 1 BDC linkers while Site 2 is located on either side of the gaps created by Group 2 linkers, creating a stacking of methanol molecules along the principal channel direction (Fig. 9; Graham et al., 2014). The ability to atomistically model the methanol molecules is a notable result since structural data concerning adsorbate location is uncommon for MOFs, especially for those under high pressure. Diffraction data were collected up to $3.0 \mathrm{GPa}$ and it was found that the methanol uptake was mediated by a gradual population of the adsorption sites. Site 1 is clearly the preferred site since it becomes fully occupied at $0.3 \mathrm{GPa}$. The Site 2 occupancy increases gradually, peaking at $80 \%$ at $1.1 \mathrm{GPa}$ and remaining at approximately this level for the remainder of the pressure regime. As in the previous discussion of MOF-5 and HKUST1 , the guest inclusion in $\mathrm{Sc}_{2} \mathrm{BDC}_{3}$ delays the onset of amorphization. Direct compression is observed using the nonpenetrating FC-77 instead of methanol, although only one data set could be collected at $0.14 \mathrm{GPa}$ as $\mathrm{Sc}_{2} \mathrm{BDC}_{3}$ became amorphous above this pressure.

The insight into the superfilling mechanism was improved by the models of $\mathrm{Sc}_{2} \mathrm{BDC}_{3}$ in methanol. It is noteworthy that the non-H atom bonding distances between pairs of Site 1 $(2.701 \AA)$ and Site $2(2.422 \AA)$ molecules at $0.6 \mathrm{GPa}$ are in the range of hydrogen-bonding interaction distances observed for hydroxyl groups in the solid state. The minimum $\mathrm{O} \cdots \mathrm{O}$ distance in solid methanol crystallized at $4.0 \mathrm{GPa}$, for example, measures $2.425 \AA$. The pore-filling mechanism here was nicely complemented by radial distribution functions calculated from MD simulations by analysing the distances between the oxygen and hydroxyl $\mathrm{H}$ atoms for different molecules of adsorbed methanol. These indicated that Site 1 methanol molecules exhibit a strong preference for hydrogen bonding to other Site 1 molecules, while methanol molecules adsorbed on Site 2 are equally likely to form hydrogen bonds with other
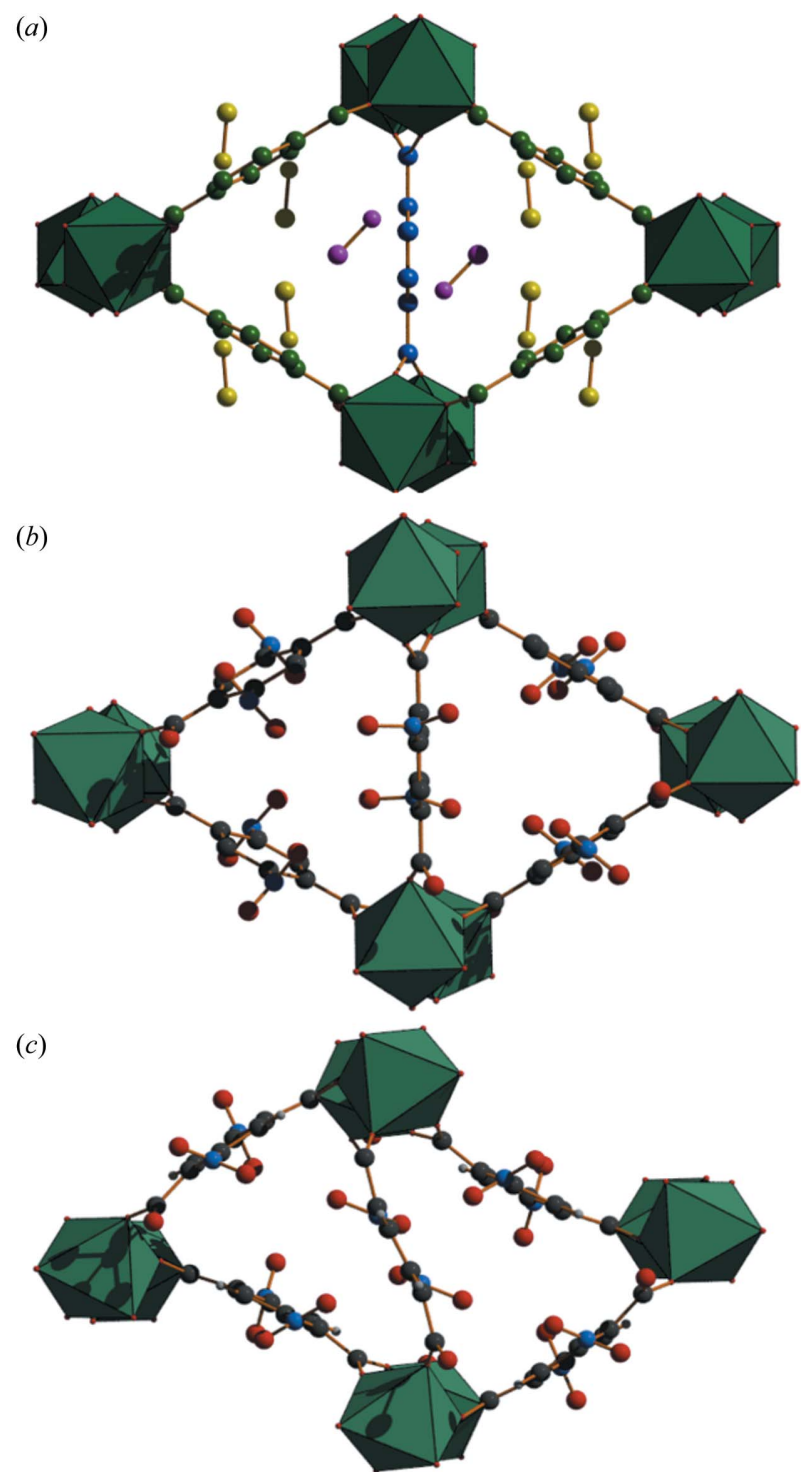

(d)
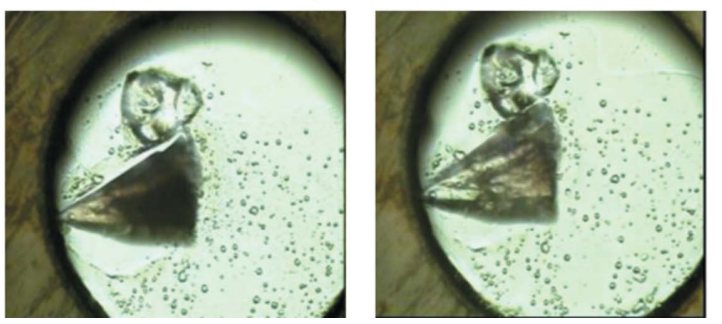

Figure 9

(a) Pore structure of $\mathrm{Sc}_{2} \mathrm{BDC}_{3}$ with Groups 1 and 2 coloured green and blue, respectively. Site 1 and Site 2 methanol molecules are coloured purple and yellow respectively. $\mathrm{Sc}_{2}\left(\mathrm{NO}_{2}-\mathrm{BDC}\right)_{3}$ at $(b)$ ambient pressure and $(c) 0.8 \mathrm{GPa}$ on direct compression. Note, the $\mathrm{ScO}_{6}$ octahedra tilt by approximately $25^{\circ}$ on undergoing the transition, causing the collapse of the one-dimensional porous network. Colour scheme for $(b)$ and $(c)$ : $\mathrm{O}$, red; $\mathrm{C}$, grey; $\mathrm{N}$, blue and $\mathrm{ScO} 6$ octahedra, green. $\mathrm{H}$ atoms have been removed for clarity. (d) Optical image of $\mathrm{Sc}_{2} \mathrm{BDC}_{3}$ (lower crystal) loaded in Fluorinert $\mathrm{FC}-77$ at $0.40 \mathrm{GPa}$ (left) and $0.10 \mathrm{GPa}$ (right) after decompression. The colourless crystal sitting above $\mathrm{Sc}_{2} \mathrm{BDC}_{3}$ is a chip of ruby, which is used as a pressure calibrant. Figure adapted from Graham et al. (2014). 
Site 2 molecules and also with $\mathrm{H}$ atoms of methanol molecules adsorbed within the same pore at Site 1 . This suggests that the arrangement of framework atoms near Site 1 is more conducive to hydrogen bond formation than the geometry at Site 2 and results in a preferential filling of Site 1.

(ii) $\mathbf{S c}_{2}\left(\mathrm{NO}_{2} \text {-BDC }\right)_{3}$ : This work on $\mathrm{Sc}_{2} \mathrm{BDC}_{3}$ also addresses one other typical theme in synthetic MOF research but otherwise not reflected in any other high-pressure MOF studies: the effect of derivatization of the organic linker. The nitro modification of $\mathrm{Sc}_{2} \mathrm{BDC}_{3}, \mathrm{Sc}_{2}\left(\mathrm{NO}_{2}-\mathrm{BDC}\right)_{3}$ (Mowat et al., 2011), crystallizes in the monoclinic space group $C 2 / c$ and is topologically very similar to $\mathrm{Sc}_{2} \mathrm{BDC}_{3}$, although the nitro group is disordered by inversion and rotation, thus breaking the Fddd symmetry in the native form. The most striking feature of the nitro-derivatized MOF is how the resistance of the framework to pressure is massively increased as a result of the modification. Compressed in FC-77, amorphization is not induced in $\mathrm{Sc}_{2}\left(\mathrm{NO}_{2}-\mathrm{BDC}\right)_{3}$ until $2.6 \mathrm{GPa}$.

This result is in keeping with previous studies (e.g. see \$2.1) which show higher bulk and elastic moduli in denser phases, although this is usually, by definition, at the expense of the flexibility and potential for extreme structural rearrangement. Surprisingly then, $\mathrm{Sc}_{2}\left(\mathrm{NO}_{2}-\mathrm{BDC}\right)_{3}$ undergoes a drastic distortion and collapse of the one-dimensional channels via a rotation of the $\mathrm{ScO}_{6}$ octahedra (Figs. $9 b$ and $c$ ) at $0.8 \mathrm{GPa}$. This single-crystal to single-crystal phase transition is accompanied by a change in the space group from monoclinic $C 2 / c$ to orthorhombic $F d d 2$. No high-pressure structural data or pore content data could be obtained for $\mathrm{Sc}_{2}\left(\mathrm{NO}_{2}-\mathrm{BDC}\right)_{3}$ in methanol due to poor crystal quality. However, a slight NLC in the $a$-axis (channel direction) indicates that methanol is squeezed into the framework to some extent. The increase in length of the $a$-axis in $\mathrm{Sc}_{2}\left(\mathrm{NO}_{2}-\mathrm{BDC}\right)_{3}$, is much less dramatic than in $\mathrm{Sc}_{2} \mathrm{BDC}_{3}$ and this reflects the likely lower uptake. This is undoubtedly due to the presence of the bulky $\mathrm{NO}_{2}$ side groups, with the overall effect of pressure causing a volume reduction to $0.9 \mathrm{GPa}$, rather than expansion which is observed in $\mathrm{Sc}_{2} \mathrm{BDC}_{3}$ to $0.6 \mathrm{GPa}$ in methanol. This result is also consistent with the methanol adsorption isotherm under ambient pressure conditions, which shows a significantly reduced uptake of methanol in $\mathrm{Sc}_{2}\left(\mathrm{NO}_{2}-\mathrm{BDC}\right)_{3}$ compared with the native $\mathrm{Sc}_{2} \mathrm{BDC}_{3}$ (Graham et al., 2014).

\subsection{Post-synthetic modification}

We have recently presented the first example of a pressureinduced post-synthetic modification (PSM) of a MOF (McKellar et al., 2014). PSM is the covalent (or dative) modification of a MOF after it has been synthesized and is a very elegant example of solid-state chemistry since it makes possible the synthesis of frameworks which may be unachievable by established synthetic routes (Cohen, 2012; Wang $\&$ Cohen, 2009). This technique has attracted much attention over recent years since it offers the potential to tune pore size, shape and functionality of a crystalline framework while conserving the integrity of the structure. For clarity it is worth

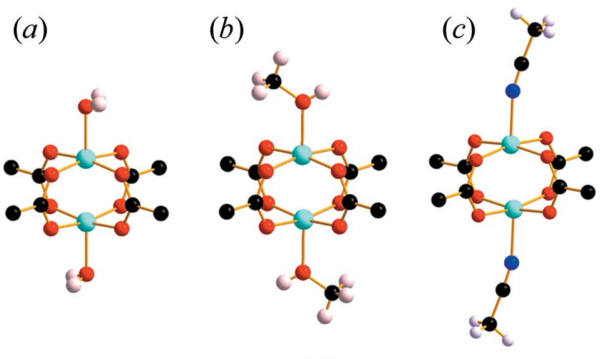

(d)

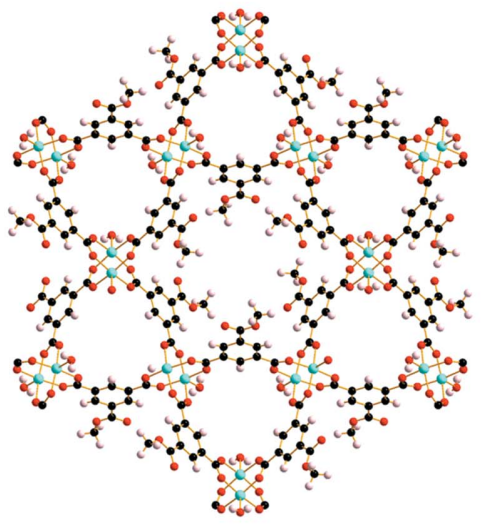

(e)

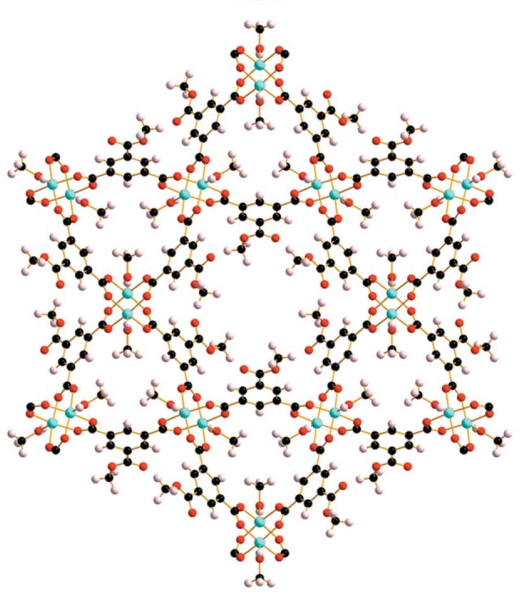

(f)

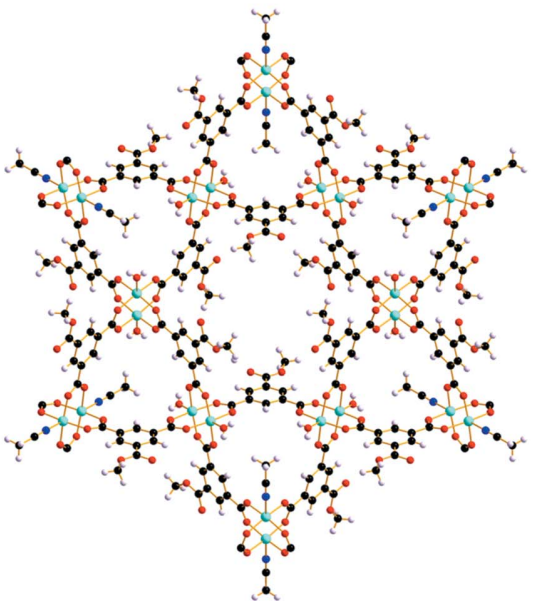

Figure 10

$\mathrm{Cu}$ paddle wheel units in $(a)$ STAM-1, (b) STAM- $1_{\mathrm{MeOH}}$ and (c) STAM$1_{\mathrm{MeCN}}$. Reduction in size of the 'hydrophilic' channel resulting from ligand exchange in $(d)$ STAM-1, $(e)$ STAM- $1_{\mathrm{MeOH}},(f)$ STAM- $1_{\mathrm{MeCN}}$, viewed parallel to the $c$-axis. The part-occupied acetonitrile ligands are shown at full occupancy in $(c)$, but the part-exchange is represented in $(f)$ by showing coordination at only one of the potential three coordination sites. Image adapted from McKellar et al. (2014). 
pointing out that our previous discussions of the high-pressure behaviour of MOFs are not PSMs under the above definition.

PSM tends to be achieved by either covalent modification of the organic linker (Seo et al., 2000; Gadzikwa et al., 2009) or by exposing a free site on the metal to facilitate ligand exchange (Chui et al., 1999; Bae et al., 2009). In our work we reported a number of single-step ligand exchanges of the MOF, STAM-1 (St Andrews MOF-1; $\left[\mathrm{Cu}_{3} \mathrm{O}_{21} \mathrm{C}_{30} \mathrm{H}_{24}\right]_{n} \cdot 5 n\left(\mathrm{H}_{2} \mathrm{O}\right)$ ). STAM-1 (Mohideen et al., 2011) is comprised of monomethyl-esterified BTC ligands linking five-coordinate $\mathrm{Cu}$ paddle wheels. These dimeric $\mathrm{Cu}$ tetracarboxylate units form four symmetryequivalent equatorial $\mathrm{Cu}-\mathrm{O}$ bonds and an axial Jahn-Teller distorted $\mathrm{Cu}-\mathrm{O}$ bond to a coordinated water molecule. The preparation of both HKUST-1 and STAM-1 involve similar reaction conditions. The synthesis of HKUST-1 involves reacting $\mathrm{Cu}\left(\mathrm{NO}_{3}\right)_{2} \cdot 3 \mathrm{H}_{2} \mathrm{O}$ with $\mathrm{BTC}$ in a Teflon-lined autoclave using ethanol as a solvent. Exchanging the solvent for a 50:50 mixture of water:methanol results in the formation of STAM-1 (Fig. 10), in which the BTC linker is monoesterified during synthesis. The resulting framework forms interdigitated layers with two types of channel: one lined by the ester groups (hydrophobic), and others lined by three axial water molecules (hydrophilic), as shown in Fig. 10(d). There are one hydrophobic and two hydrophilic channels per unit cell.

Using in situ single-crystal XRD we found that the axial water molecule is remarkably labile and, when STAM-1 is soaked in methanol under ambient conditions, undergoes a single-step ligand exchange with the solvent molecule at the axial coordination site (referred to as STAM- $1_{\mathrm{MeOH}}$, Fig. 10e; McKellar et al., 2014). This has a dramatic effect on the structure, essentially turning the open hydrophilic channels into discrete hydrophobic pores as a result of the penetration of methyl groups into the channel, which also decreases the solvent-accessible diameter of the channels from 1.79 to $0.49 \AA$. The modified crystal is stable under ambient conditions once removed from the methanol solvent. This result is particularly interesting considering that methanol is used in the original reaction conditions (with water in a 50:50 mixture), implying that the PSM approach is the only route to producing the methanol-modified structure. High-pressure single-crystal XRD using various organic solvents as hydrostatic media was found to be a useful tool to fully understand this PSM behaviour, revealing initially a strict dependence on the molecular size of the solvent.

In methanol, STAM-1 is stable to $5.7 \mathrm{GPa}$ since the methanol fills the small hydrophilic channel (and undergoes ligand exchange) and also superfills the large hydrophobic channel. IPA, however, is too large a molecule to fit inside the small channel, and only fills the large hydrophobic channel. Only half of the available void space is therefore 'superfilled' with IPA and STAM-1 is stable to only $2.4 \mathrm{GPa}$. In ethanol, even at ambient pressure, the crystal instantly becomes polycrystalline upon immersion. We hypothesized that an analogous ligand exchange occurs with ethanol, as observed in methanol, but that the steric hindrance caused by the larger size of the ethanol molecule causes a strain-induced collapse of the framework. This hypothesis was backed up by the results when acetonitrile (approximately the same size as ethanol) was used as a hydrostatic medium. No ligand exchange was observed in STAM-1 with acetonitrile at ambient pressure, but when pressure was applied in a DAC, the axial water ligand exchanged at $0.3 \mathrm{GPa}$, to yield STAM$1_{\mathrm{MeCN}}$. However, the occupancy of each acetonitrile ligand is one third and thus occupies only one of the potential three coordination sites penetrating the hydrophilic channel (Fig. 10f). By only part-exchanging with the axial water ligand, steric strain between adjacent ligands is prevented. No further pressure measurements could be obtained in acetonitrile since the solvent froze at $\sim 0.6 \mathrm{GPa}$.

In addition to revealing a sensitivity to the size of the hydrostatic liquid, our high-pressure experiments also highlighted the sensitivity of STAM-1 to the functionality of the solvent. Other than the differences already observed between ethanol and acetonitrile, we observed no ligand exchange with the similarly sized acetaldehyde. Instead, acetaldehyde superfills both channels in STAM-1 and highlights how ligand exchange affects the direction of the framework compression. Up to 5.4 and $5.1 \mathrm{GPa}$, respectively, there is an almost identical reduction in the unit-cell volume of STAM-1 in acetaldehyde and methanol; by 304.5 (4) and 304.4 (4) $\AA^{3}$, respectively. However, in acetaldehyde STAM-1 is significantly more compressible along the $a / b$ axes than STAM$1_{\mathrm{MeOH}}$, which instead accommodates the pressure increase almost entirely along the $c$-axis due to the stiffness afforded by the methanol ligands in the $a / b$ plane (Fig. 10). Given the variety of structural responses observed in STAM-1 with various solvents, this study is a demonstration of how pressure is a useful tool to probe the susceptibility of certain types of framework to PSM and facilitate the discovery of new materials.

\section{Pressure-induced amorphization}

Almost every diffraction study describing the effect of pressure on MOFs, at some stage, describes the onset of amorphization at elevated pressures. The amorphization pressure can be varied significantly depending on both the mechanism of applying pressure, the hydrostatic liquid used and on derivitization of the organic linker within the framework. In MOF-5, for example, compression to $3.5 \mathrm{MPa}$ in a hydraulic press causes the framework to collapse (Hu \& Zhang, 2010). Here, Raman spectroscopy of the crystalline and amorphous phases showed that the vibrational modes in both were similar, indicating that the local structure was retained on undergoing the transition. Interestingly, in our previous high-pressure study of MOF-5 where DEF was used as a hydrostatic liquid (and was present in the crystal prior-to applying pressure), amorphization did not occur until above 3.2 GPa (\$4.2.1). The uptake of guest molecules on increasing pressure delaying the onset of amorphization was also seen in $\mathrm{Sc}_{2} \mathrm{BDC}_{3}$ and its nitro equivalent $\mathrm{Sc}_{2}\left(\mathrm{NO}_{2}-\mathrm{BDC}\right)_{3}$ (\$4.2.3). In the native $\mathrm{Sc}_{2} \mathrm{BDC}_{3}$, amorphization occurs on direct compression using FC-77 as a hydrostatic liquid at $0.14 \mathrm{GPa}$, and causes the crystal to become opaque (Fig. 9d). The transition here is fully rever- 
sible, returning to the crystalline (colourless and transparent) on decreasing pressure. Raman spectroscopy, as in MOF-5, was used to show that the connectivity in the two phases was very similar. On increasing pressure on the nitro derivative $\mathrm{Sc}_{2}\left(\mathrm{NO}_{2}-\mathrm{BDC}\right)_{3}$ quite different behaviour occurs, with the sample undergoing a transition to a more dense crystalline phase [see §4.2.3(ii)]. Unusual behaviour has been observed in the cyanide framework $\mathrm{Zn}(\mathrm{CN})_{2}$, which becomes amorphous at $3 \mathrm{GPa}$, but only when exposed to X-rays (Lapidus et al., 2013). The role that ionizing radiation has on this process is not fully understood, and is an area ripe for exploration.

Most of the literature on amorphous porous MOFs involves ZIF-8 which undergoes irreversible amorphization at approximately $1.4 \mathrm{GPa}$ in FC-70, or $0.34 \mathrm{GPa}$ under nonhydrostatic conditions. If ethanol is used as a hydrostatic liquid, the pressure of the induced amorphization is delayed. PDF data collected on both crystalline and amorphous ZIF-8 indicates that the $\mathrm{Zn}$-imidazolate- $\mathrm{Zn}$ link is retained, while IR spectroscopy has shown that the transition is reversible up to $1.6 \mathrm{GPa}$, although pressures above this, and up to $39 \mathrm{GPa}$ are irreversible. The recovered product is neither the original crystalline ZIF-8 phase or the recovered amorphous ZIF-8, with the recovered product yet to be fully characterized, although the stretching frequencies (except for those within the ring stretch region for $\mathrm{C}=\mathrm{N}$ and $\mathrm{C}-\mathrm{H}$ ), appear to be similar to crystalline ZIF-8 (Hu et al., 2011).

The amorphous material has a significantly reduced absorption capacity from BET analysis, and differences have even been observed depending on the mechanism of amorphization (Bennett et al., 2013). Pressure-induced amorphization of ZIF-8, for example, leads to a much more porous material than amorphization through ball-milling techniques. This would seem to suggest that the pore structure is still intact upon amorphization, and that the structure of the two amorphous phases must be different.

The porosity, although diminished in pressure-induced amorphous ZIF-8, has also been used to trap molecular $\mathrm{I}_{2}$ in the pores. Interestingly, collapsing the ZIF-8 framework around molecular $I_{2}$ showed a greater retention of the adsorbed molecule on heating than in the crystalline ZIF-8 phase (Sava et al., 2011).

Most of the other studies carried out so far have involved other ZIFs, although in general, these have been on the much denser ZIF-1, ZIF-3 and ZIF-4 frameworks. For a much more detailed description specifically on amorphization in MOFs, particularly of these denser phases, we recommend reading the excellent review by Bennett \& Cheetham (2014), which describes this in much more detail.

\section{Looking forward}

The effect of pressure on molecular porous materials has grown substantially over the last 10 years or so, with several good reviews on the subject (Moggach \& Parsons, 2009; Moggach, Parsons \& Wood, 2008; Tidey et al., 2014). It is inevitable that the number of studies describing the effect of pressure on MOFs will increase substantially in the years to come, and that the reasons for this are clear. High-pressure crystallographic studies of MOFs allows us, in a systematic fashion, to explore the uptake of guest species and the subsequent effect of any changes in the framework geometry, while simultaneously testing their mechanical strength. In a way, high-pressure studies allow us to probe the potential energy landscape of the framework experimentally, and observe the effect of different guests on the framework. Recently, the use of amorphous MOFs for encapsulating molecules has proven very effective, and extremely interesting, but clearly a lot more needs to be done before the mechanism and structure of the materials is properly understood. The fact that porous materials can be made from nonporous structures is also a remarkable discovery. Characterizing non-crystalline materials is a challenge in itself, and this again would seem to be an area worthy of much further investigation, and we would not be surprised if this became a growth area in the field. The effect that the uptake of guest species has on the electrical conductivity, magnetism and catalytic activity of MOFs are also areas where we envisage growth and an increased level of interest, in keeping with the growing interest in MOFs in these applications in general. The primary effect of being able to force hydrophilic molecules into hydrophobic pores, for example, and significantly increase the adsorption of guest molecules into the pores (a mechanism which we described here as 'superfilling'), seems to be an obvious route to achieving unusual chemistry inside MOFs, without the need to rely solely on diffusion of material into the pores. It is inevitable that other anomalous mechanical behaviour is also discovered in MOFs, such as auxeticity (i.e. the existence of negative Poisson's ratio) which has already been discovered and thoroughly studied in the 1990s in zeolitic materials, as discussed recently by Coudert (2015) and Tan et al. (2015). We hope that high-pressure studies in the future will help us to better understand and manipulate the molecular solid-state chemistry of MOFs, and we look forward to seeing many more studies in this field in the years to come.

\section{References}

Abrahams, B. F., Haywood, M. G., Robson, R. \& Slizys, D. A. (2003). Angew. Chem. Int. Ed. 42, 1112-1115.

Aguado, S., Bergeret, G., Titus, M. P., Moizan, V., Nieto-Draghi, C., Bats, N. \& Farrusseng, D. (2011). New J. Chem. 35, 546-550.

Allendorf, M. D., Bauer, C. A., Bhakta, R. K. \& Houk, R. J. T. (2009). Chem. Soc. Rev. 38, 1330-1352.

Allendorf, M. D., Houk, R. J. T., Andruszkiewicz, L., Talin, A. A., Pikarsky, J., Choudhury, A., Gall, K. A. \& Hesketh, P. J. (2008). J. Am. Chem. Soc. 130, 14404-14405.

Ameloot, R., Stappers, L., Fransaer, J., Alaerts, L., Sels, B. F. \& De Vos, D. E. (2009). Chem. Mater. 21, 2580-2582.

Angel, R. J., Allan, D. R., Miletich, R. \& Finger, L. W. (1997). J. Appl. Cryst. 30, 461-466.

Baburin, I. A., Leoni, S. \& Seifert, G. (2008). J. Phys. Chem. B, 112, 9437-9443.

Bae, Y.-S., Farha, O. K., Hupp, J. T. \& Snurr, R. Q. (2009). J. Mater. Chem. 19, 2131-2134. 
Bahr, D. F., Reid, J. A., Mook, W. M., Bauer, C. A., Stumpf, R., Skulan, A. J., Moody, N. R., Simmons, B. A., Shindel, M. M. \& Allendorf, M. D. (2007). Phys. Rev. B, 76, 184106.

Banerjee, D., Kim, S. J., Wu, H., Xu, W., Borkowski, L. A., Li, J. \& Parise, J. B. (2011). Inorg. Chem. 50, 208-212.

Banerjee, R., Phan, A., Wang, B., Knobler, C., Furukawa, H., O'Keeffe, M. \& Yaghi, O. M. (2008). Science, 319, 939-943.

Barrera, G. D., Bruno, J. A. O., Barron, T. H. K. \& Allan, N. L. (2005). J. Phys. Condens. Matter, 17, R217-R252.

Baughman, R. H. (2003). Nature, 425, 667.

Baughman, R. H., Stafstrom, S., Cui, C. X. \& Dantas, S. O. (1998). Science, 279, 1522-1524.

Bennett, T. D. \& Cheetham, A. K. (2014). Acc. Chem. Res. 47, 15551562.

Bennett, T. D., Goodwin, A. L., Dove, M. T., Keen, D. A., Tucker, M. G., Barney, E. R., Soper, A. K., Bithell, E. G., Tan, J. C. \& Cheetham, A. K. (2010). Phys. Rev. Lett. 104, 115503.

Bennett, T. D., Saines, P. J., Keen, D. A., Tan, J.-C. \& Cheetham, A. K. (2013). Chem. Eur. J. 19, 7049-7055.

Bennett, T. D., Tan, J.-C., Moggach, S. A., Galvelis, R., MellotDraznieks, C., Reisner, B. A., Thirumurugan, A., Allan, D. R. \& Cheetham, A. K. (2010). Chem. Eur. J. 16, 10684-10690.

Bergh, J. van den, Gücüyener, C., Pidko, E. A., Hensen, E. J. M., Gascon, J. \& Kapteijn, F. (2011). Chem. Eur. J. 17, 8832-8840.

Biswas, M. M. \& Cagin, T. (2011). Mater. Chem. Phys. 131, 44-51.

Blake, A. J., Champness, N. R., Easun, T. L., Allan, D. R., Nowell, H., George, M. W., Jia, J. \& Sun, X.-Z. (2010). Nat. Chem. 2, 688694.

Boldyreva, E. V., Ivashevskaya, S. N., Sowa, H., Ahsbahs, H. \& Weber, H. P. (2005). Z. Kristallogr. 220, 50-57.

Bouëssel du Bourg, L., Ortiz, A. U., Boutin, A. \& Coudert, F.-X. (2014). APL Mater. 2, 124110.

Bureekaew, S., Sato, H., Matsuda, R., Kubota, Y., Hirose, R., Kim, J., Kato, K., Takata, M. \& Kitagawa, S. (2010). Angew. Chem. Int. Ed. 49, 7660-7664.

Bux, H., Chmelik, C., van Baten, J. M., Krishna, R. \& Caro, J. (2010). Adv. Mater. 22, 4741-4743.

Bux, H., Liang, F., Li, Y., Cravillon, J., Wiebcke, M. \& Caro, J. (2009). J. Am. Chem. Soc. 131, 16000-16001.

Byrne, P. J., Richardson, P. J., Chang, J., Kusmartseva, A. F., Allan, D. R., Jones, A. C., Kamenev, K. V., Tasker, P. A. \& Parsons, S. (2012). Chem. Eur. J. 18, 7738-7748.

Cai, W. Z. \& Katrusiak, A. (2014). Nat. Commun. 5, 4337.

Cairns, A. B., Catafesta, J., Levelut, C., Rouquette, J., van der Lee, A., Peters, L., Thompson, A. L., Dmitriev, V., Haines, J. \& Goodwin, A. L. (2013). Nat. Mater. 12, 212-216.

Cairns, A. B. \& Goodwin, A. L. (2015). Phys. Chem. Chem. Phys. 17, 20449-20465.

Cairns, A. B., Thompson, A. L., Tucker, M. G., Haines, J. \& Goodwin, A. L. (2012). J. Am. Chem. Soc. 134, 4454-4456.

Cavka, J. H., Jakobsen, S., Olsbye, U., Guillou, N., Lamberti, C., Bordiga, S. \& Lillerud, K. P. (2008). J. Am. Chem. Soc. 130, 1385013851 .

Champness, N. R. (2011). Dalton Trans. 40, 10311-10315.

Chaplais, G., Simon-Masseron, A., Porcher, F., Lecomte, C., BazerBachi, D., Bats, N. \& Patarin, J. (2009). Phys. Chem. Chem. Phys. 11, 5241-5245.

Chapman, K. W. \& Chupas, P. J. (2007). J. Am. Chem. Soc. 129, 1009010091.

Chapman, K. W., Chupas, P. J. \& Kepert, C. J. (2005). J. Am. Chem. Soc. 127, 15630-15636.

Chapman, K. W., Halder, G. J. \& Chupas, P. J. (2008). J. Am. Chem. Soc. 130, 10524-10526.

Chapman, K. W., Halder, G. J. \& Chupas, P. J. (2009). J. Am. Chem. Soc. 131, 17546-17547.

Cheetham, A. K. \& Rao, C. N. R. (2007). Science, 318, 58-59.

Cheetham, A. K., Rao, C. N. R. \& Feller, R. K. (2006). Chem. Commun. pp. 4780-4795.
Chen, B. L., Xiang, S. C. \& Qian, G. D. (2010). Acc. Chem. Res. 43, $1115-1124$.

Cheon, Y. E., Park, J. \& Suh, M. P. (2009). Chem. Commun. pp. 54365438.

Chui, S. S. Y., Lo, S. M. F., Charmant, J. P. H., Orpen, A. G. \& Williams, I. D. (1999). Science, 283, 1148-1150.

Cohen, S. M. (2012). Chem. Rev. 112, 970-1000.

Colligan, M., Forster, P. M., Cheetham, A. K., Lee, Y., Vogt, T. \& Hriljac, J. A. (2004). J. Am. Chem. Soc. 126, 12015-12022.

Collings, I. E., Cairns, A. B., Thompson, A. L., Parker, J. E., Tang, C. C., Tucker, M. G., Catafesta, J., Levelut, C., Haines, J., Dmitriev, V., Pattison, P. \& Goodwin, A. L. (2013). J. Am. Chem. Soc. 135, 7610-7620.

Coudert, F.-X. (2015). Chem. Mater. 27, 1905-1916.

Cussen, E. J., Claridge, J. B., Rosseinsky, M. J. \& Kepert, C. J. (2002). J. Am. Chem. Soc. 124, 9574-9581.

Cychosz, K. A., Ahmad, R. \& Matzger, A. J. (2010). Chem. Sci. 1, 293-302.

Deckman, H. W., Kortunov, P., Ni, Z., Paur, C. S., Reyes, S. C., Zengel, J., Santiesteban, J. G. \& Santiesteban, L. R. (2015). Patents WO2009105255-A2; US2009214407-A1; WO2009105255-A3; AU2009215790-A1; EP2249947-A2; CA2716323-A1; CN102015065-A; EP2249947-B1; US8142745-B2; ES2376615-T3; AU2009215790-B2.

Deckman, H. W., Kortunov, P., Ni, Z., Paur, C. S., Zengel, J., Reyes, S. C., Santiesteban, J. G., Sentiesteben, J. G. \& Santiesteban, L. R. (2015). Patents WO2009105251-A1; US2009211440-A1; US2009211441-A1; US2009216059-A1; AU2009215786-A1; EP2254683-A1; CA2716322-A1; CN102036734-A; EP2254683-B1; US8071063-B2; US8142746-B2; US8192709-B2; ES2378131-T3.

Dinca, M. \& Long, J. R. (2005). J. Am. Chem. Soc. 127, 93769377.

Dubbeldam, D., Walton, K. S., Ellis, D. E. \& Snurr, R. Q. (2007). Angew. Chem. Int. Ed. 46, 4496-4499.

Eddaoudi, M., Kim, J., Rosi, N., Vodak, D., Wachter, J., O'Keeffe, M. \& Yaghi, O. M. (2002). Science, 295, 469-472.

Evans, K. E. \& Alderson, A. (2000). Adv. Mater. 12, 617-628.

Fairen-Jimenez, D., Galvelis, R., Torrisi, A., Gellan, A. D., Wharmby, M. T., Wright, P. A., Mellot-Draznieks, C. \& Düren, T. (2012). Dalton Trans. 41, 10752-10762.

Fairen-Jimenez, D., Moggach, S. A., Wharmby, M. T., Wright, P. A., Parsons, S. \& Düren, T. (2011). J. Am. Chem. Soc. 133, 89008902.

Férey, G. (2008). Chem. Soc. Rev. 37, 191-214.

Fletcher, A. J., Thomas, K. M. \& Rosseinsky, M. J. (2005). J. Solid State Chem. 178, 2491-2510.

Forster, P. M. \& Cheetham, A. K. (2002). Angew. Chem. Int. Ed. 41, 457-459.

Fortes, A. D., Suard, E. \& Knight, K. S. (2011). Science, 331, 742746.

Fu, R. B., Wu, X. T., Hu, S. M., Zhang, J. J., Fu, Z. Y. \& Du, W. X. (2003). Polyhedron, 22, 2739-2744.

Furukawa, H., Cordova, K. E., O'Keeffe, M. \& Yaghi, O. M. (2013). Science, 341, 1230444.

Gadzikwa, T., Farha, O. K., Mulfort, K. L., Hupp, J. T. \& Nguyen, S. T. (2009). Chem. Commun. pp. 3720-3722.

Gagnon, K. J., Beavers, C. M. \& Clearfield, A. (2013). J. Am. Chem. Soc. 135, 1252-1255.

Gagnon, K. J., Perry, H. P. \& Clearfield, A. (2012). Chem. Rev. 112, 1034-1054.

Goodwin, A. L., Calleja, M., Conterio, M. J., Dove, M. T., Evans, J. S. O., Keen, D. A., Peters, L. \& Tucker, M. G. (2008). Science, 319, 794-797.

Goodwin, A. L., Keen, D. A. \& Tucker, M. G. (2008). Proc. Natl Acad. Sci. USA, 105, 18708-18713.

Goodwin, A. L. \& Kepert, C. J. (2005). Phys. Rev. B, 71, 140301.

Gould, J. A., Rosseinsky, M. J., Warren, J. E. \& Moggach, S. (2014). Z. Kristallogr. 229, 123-128. 
Gouldstone, A., Chollacoop, N., Dao, M., Li, J., Minor, A. M. \& Shen, Y.-L. (2007). Acta Mater. 55, 4015-4039.

Graham, A. J., Allan, D. R., Muszkiewicz, A., Morrison, C. A. \& Moggach, S. A. (2011). Angew. Chem. Int. Ed. 50, 11138-11141.

Graham, A. J., Banu, A.-M., Düren, T., Greenaway, A., McKellar, S. C., Mowat, J. P. S., Ward, K., Wright, P. A. \& Moggach, S. A. (2014). J. Am. Chem. Soc. 136, 8606-8613.

Graham, A. J., Tan, J.-C., Allan, D. R. \& Moggach, S. A. (2012). Chem. Commun. 48, 1535-1537.

Greathouse, J. A. \& Allendorf, M. D. (2008). J. Phys. Chem. C, 112, 5795-5802.

Grima, J. N., Attard, D., Caruana-Gauci, R. \& Gatt, R. (2011). Scr. Mater. 65, 565-568.

Gücüyener, C., van den Bergh, J., Gascon, J. \& Kapteijn, F. (2010). J. Am. Chem. Soc. 132, 17704-17706.

Guillerm, V., Ragon, F., Dan-Hardi, M., Devic, T., Vishnuvarthan, M., Campo, B., Vimont, A., Clet, G., Yang, Q., Maurin, G., Férey, G., Vittadini, A., Gross, S. \& Serre, C. (2012). Angew. Chem. Int. Ed. 51, 9267-9271.

Guillou, N., Livage, C., Drillon, M. \& Férey, G. (2003). Angew. Chem. Int. Ed. 42, 5314-5317.

Haines, J., Cambon, O., Levelut, C., Santoro, M., Gorelli, F. \& Garbarino, G. (2010). J. Am. Chem. Soc. 132, 8860-8861.

Haines, J., Chateau, C., Leger, J. M., Bogicevic, C., Hull, S., Klug, D. D. \& Tse, J. S. (2003). Phys. Rev. Lett. 91, 015503.

Haldoupis, E., Nair, S. \& Sholl, D. S. (2010). J. Am. Chem. Soc. 132, 7528-7539.

Han, S. S. \& Goddard, W. A. III (2007). J. Phys. Chem. C, 111, 1518515191.

Hazen, R. M. (1983). Science, 219, 1065-1067.

Hazen, R. M. \& Finger, L. W. (1984). J. Appl. Phys. 56, 1838-1840.

Hazen, R. M. \& Prewitt, C. T. (1977). Am. Mineral. 62, 309-315.

Herm, Z. R., Swisher, J. A., Smit, B., Krishna, R. \& Long, J. R. (2011). J. Am. Chem. Soc. 133, 5664-5667.

Horcajada, P., Chalati, T., Serre, C., Gillet, B., Sebrie, C., Baati, T., Eubank, J. F., Heurtaux, D., Clayette, P., Kreuz, C., Chang, J. S., Hwang, Y. K., Marsaud, V., Bories, P. N., Cynober, L., Gil, S., Férey, G., Couvreur, P. \& Gref, R. (2010). Nat. Mater. 9, 172-178.

Hu, Y., Kazemian, H., Rohani, S., Huang, Y. \& Song, Y. (2011). Chem. Commun. 47, 12694-12696.

Hu, Y. H. \& Zhang, L. (2010). Phys. Rev. B, 81, 174103.

Huang, X. C., Li, D. \& Chen, X. M. (2006). CrystEngComm, 8, 351355.

Huang, X. C., Lin, Y. Y., Zhang, J. P. \& Chen, X. M. (2006). Angew. Chem. Int. Ed. 45, 1557-1559.

Iwamoto, T. (1996). J. Incl. Phenom. Macrocycl Chem. 24, 61-132.

Katrusiak, A. (2008). Acta Cryst. A64, 135-148.

Kaye, S. S., Dailly, A., Yaghi, O. M. \& Long, J. R. (2007). J. Am. Chem. Soc. 129, 14176-14177.

Kim, J., Chen, B. L., Reineke, T. M., Li, H. L., Eddaoudi, M., Moler, D. B., O'Keeffe, M. \& Yaghi, O. M. (2001). J. Am. Chem. Soc. 123, 8239-8247.

Kitagawa, S., Kitaura, R. \& Noro, S. (2004). Angew. Chem. Int. Ed. 43, 2334-2375.

Kitagawa, S. \& Kondo, M. (1998). Bull. Chem. Soc. Jpn, 71, 17391753.

Kitazawa, T., Kikuyama, T., Takeda, M. \& Iwamoto, T. (1995). J. Chem. Soc. Dalton Trans. pp. 3715-3720.

Kreno, L. E., Leong, K., Farha, O. K., Allendorf, M., Van Duyne, R. P. \& Hupp, J. T. (2012). Chem. Rev. 112, 1105-1125.

Kurmoo, M. (2009). Chem. Soc. Rev. 38, 1353-1379.

Lan, A., Li, K., Wu, H., Olson, D. H., Emge, T. J., Ki, W., Hong, M. \& Li, J. (2009). Angew. Chem. Int. Ed. 48, 2334-2338.

Lapidus, S. H., Halder, G. J., Chupas, P. J. \& Chapman, K. W. (2013). J. Am. Chem. Soc. 135, 7621-7628.

Lee, J., Farha, O. K., Roberts, J., Scheidt, K. A., Nguyen, S. T. \& Hupp, J. T. (2009). Chem. Soc. Rev. 38, 1450-1459.

Lehnert, R. \& Seel, F. (1980). Z. Anorg. Allg. Chem. 464, 187-194.
Lewis, D. W., Ruiz-Salvador, A. R., Gómez, A., Rodriguez-Albelo, L. M., Coudert, F.-X., Slater, B., Cheetham, A. K. \& Mellot-Draznieks, C. (2009). CrystEngComm, 11, 2272-2276.

Li, W., Probert, M. R., Kosa, M., Bennett, T. D., Thirumurugan, A., Burwood, R. P., Parinello, M., Howard, J. A. K. \& Cheetham, A. K. (2012). J. Am. Chem. Soc. 134, 11940-11943.

Li, Y. \& Yang, R. T. (2007). Langmuir, 23, 12937-12944.

Lill, D. T. de, de Bettencourt-Dias, A. \& Cahill, C. L. (2007). Inorg. Chem. 46, 3960-3965.

Lin, X., Jia, J., Hubberstey, P., Schroeder, M. \& Champness, N. R. (2007). CrystEngComm, 9, 438-448.

Llewellyn, P. L., Bourrelly, S., Serre, C., Vimont, A., Daturi, M., Hamon, L., De Weireld, G., Chang, J.-S., Hong, D.-Y., Kyu Hwang, Y., Hwa Jhung, S. \& Férey, G. (2008). Langmuir, 24, 7245-7250.

Lock, N., Wu, Y., Christensen, M., Cameron, L. J., Peterson, V. K., Bridgeman, A. J., Kepert, C. J. \& Iversen, B. B. (2010). J. Phys. Chem. C, 114, 16181-16186.

Loiseau, T., Serre, C., Huguenard, C., Fink, G., Taulelle, F., Henry, M., Bataille, T. \& Férey, G. (2004). Chem. Eur. J. 10, 1373-1382.

Low, J. J., Benin, A. I., Jakubczak, P., Abrahamian, J. F., Faheem, S. A. \& Willis, R. R. (2009). J. Am. Chem. Soc. 131, 15834-15842.

Lu, G. \& Hupp, J. T. (2010). J. Am. Chem. Soc. 132, 7832-7833.

Lu, Z.-Z., Zhang, R., Li, Y.-Z., Guo, Z.-J. \& Zheng, H.-G. (2011). J. Am. Chem. Soc. 133, 4172-4174.

Luebbers, M. T., Wu, T., Shen, L. \& Masel, R. I. (2010). Langmuir, 26, $15625-15633$.

Lun, D. J., Waterhouse, G. I. N. \& Telfer, S. G. (2011). J. Am. Chem. Soc. 133, 5806-5809.

Mączka, M., Kadłubański, P., Freire, P. T. C., Macalik, B., Paraguassu, W., Hermanowicz, K. \& Hanuza, J. (2014). Inorg. Chem. 53, 96159624.

Mariathasan, J. W. E., Finger, L. W. \& Hazen, R. M. (1985). Acta Cryst. B41, 179-184.

Mattesini, M., Soler, J. M. \& Yndurain, F. (2006). Phys. Rev. B, 73, 094111.

McKellar, S. C., Graham, A. J., Allan, D. R., Mohideen, M. I. H., Morris, R. E. \& Moggach, S. A. (2014). Nanoscale, 6, $4163-$ 4173.

Merrill, L. \& Bassett, W. A. (1974). Rev. Sci. Instrum. 45, 290-294.

Millange, F., Serre, C. \& Férey, G. (2002). Chem. Commun. pp. 822823.

Miller, S. R., Wright, P. A., Devic, T., Serre, C., Férey, G., Llewellyn, P. L., Denoyel, R., Gaberova, L. \& Filinchuk, Y. (2009). Langmuir, 25, 3618-3626.

Miller, S. R., Wright, P. A., Serre, C., Loiseau, T., Marrot, J. \& Férey, G. (2005). Chem. Commun. pp. 3850-3852.

Millward, A. R. \& Yaghi, O. M. (2005). J. Am. Chem. Soc. 127, 1799817999.

Moggach, S. A., Allan, D. R., Morrison, C. A., Parsons, S. \& Sawyer, L. (2005). Acta Cryst. B61, 58-68.

Moggach, S. A., Allan, D. R., Parsons, S. \& Warren, J. E. (2008). J. Appl. Cryst. 41, 249-251.

Moggach, S. A., Bennett, T. D. \& Cheetham, A. K. (2009). Angew. Chem. Int. Ed. 48, 7087-7089.

Moggach, S. A., Galloway, K. W., Lennie, A. R., Parois, P., Rowantree, N., Brechin, E. K., Warren, J. E., Murrie, M. \& Parsons, S. (2009). CrystEngComm, 11, 2601-2604.

Moggach, S. A. \& Parsons, S. (2009). Spectrosc. Prop. Inorg. Organomet. Compd. 40, 324-354.

Moggach, S. A., Parsons, S. \& Wood, P. A. (2008). Crystallogr. Rev. 14, 143-184.

Mohideen, M. I. H., Xiao, B., Wheatley, P. S., McKinlay, A. C., Li, Y., Slawin, A. M. Z., Aldous, D. W., Cessford, N. F., Düren, T., Zhao, X., Gill, R., Thomas, K. M., Griffin, J. M., Ashbrook, S. E. \& Morris, R. E. (2011). Nat. Chem. 3, 304-310.

Morris, W., He, N., Ray, K. G., Klonowski, P., Furukawa, H., Daniels, I. N., Houndonougbo, Y. A., Asta, M., Yaghi, O. M. \& Laird, B. B. (2012). J. Phys. Chem. C, 116, 24084-24090. 
Mowat, J. P. S., Miller, S. R., Griffin, J. M., Seymour, V. R., Ashbrook, S. E., Thompson, S. P., Fairen-Jimenez, D., Banu, A.-M., Düren, T. \& Wright, P. A. (2011). Inorg. Chem. 50, 10844-10858.

Nijem, N., Wu, H., Canepa, P., Marti, A., Balkus, K. J. Jr, Thonhauser, T., Li, J. \& Chabal, Y. J. (2012). J. Am. Chem. Soc. 134, 1520115204.

Nugent, P., Belmabkhout, Y., Burd, S. D., Cairns, A. J., Luebke, R., Forrest, K., Pham, T., Ma, S., Space, B., Wojtas, L., Eddaoudi, M. \& Zaworotko, M. J. (2013). Nature, 495, 80-84.

Ogborn, J. M., Collings, I. E., Moggach, S. A., Thompson, A. L. \& Goodwin, A. L. (2012). Chem. Sci. 3, 3011-3017.

O'Keeffe, M., Peskov, M. A., Ramsden, S. J. \& Yaghi, O. M. (2008). Acc. Chem. Res. 41, 1782-1789.

Ortiz, A. U., Boutin, A., Fuchs, A. H. \& Coudert, F. X. (2013). J. Chem. Phys. 138, 174703.

Ortiz, A. U., Boutin, A., Gagnon, K. J., Clearfield, A. \& Coudert, F.-X. (2014). J. Am. Chem. Soc. 136, 11540-11545.

Park, K. S., Ni, Z., Cote, A. P., Choi, J. Y., Huang, R., Uribe-Romo, F. J., Chae, H. K., O'Keeffe, M. \& Yaghi, O. M. (2006). Proc. Natl Acad. Sci. USA, 103, 10186-10191.

Parois, P., Moggach, S. A., Lennie, A. R., Warren, J. E., Brechin, E. K., Murrie, M. \& Parsons, S. (2010). Dalton Trans. 39, 7004-7011.

Peralta, D., Chaplais, G., Simon-Masseron, A., Barthelet, K., Chizallet, C., Quoineaud, A.-A. \& Pirngruber, G. D. (2012). J. Am. Chem. Soc. 134, 8115-8126.

Peterson, V. K., Kearley, G. J., Wu, Y., Ramirez-Cuesta, A. J., Kemner, E. \& Kepert, C. J. (2010). Angew. Chem. Int. Ed. 49, 585588.

Piermarini, G. J., Block, S., Barnett, J. D. \& Forman, R. A. (1975). J. Appl. Phys. 46, 2774-2780.

Poswal, H. K., Tyagi, A. K., Lausi, A., Deb, S. K. \& Sharma, S. M. (2009). J. Solid State Chem. 182, 136-140.

Prescimone, A., Milios, C. J., Moggach, S., Warren, J. E., Lennie, A. R., Sanchez-Benitez, J., Kamenev, K., Bircher, R., Murrie, M., Parsons, S. \& Brechin, E. K. (2008). Angew. Chem. Int. Ed. 47, 2828-2831.

Prescimone, A., Milios, C. J., Sanchez-Benitez, J., Kamenev, K. V., Loose, C., Kortus, J., Moggach, S., Murrie, M., Warren, J. E., Lennie, A. R., Parsons, S. \& Brechin, E. K. (2009). Dalton Trans. pp. 48584867.

Reinsch, H., Marszałek, B., Wack, J., Senker, J., Gil, B. \& Stock, N. (2012). Chem. Commun. 48, 9486-9488.

Rosseinsky, M. J. (2004). Microporous Mesoporous Mater. 73, 1530.

Samanta, A., Furuta, T. \& Li, J. (2006). J. Chem. Phys. 125, 084714.

Sava, D. F., Rodriguez, M. A., Chapman, K. W., Chupas, P. J., Greathouse, J. A., Crozier, P. S. \& Nenoff, T. M. (2011). J. Am. Chem. Soc. 133, 12398-12401.

Seo, J. S., Whang, D., Lee, H., Jun, S. I., Oh, J., Jeon, Y. J. \& Kim, K. (2000). Nature, 404, 982-986.

Serra-Crespo, P., Dikhtiarenko, A., Stavitski, E., Juan-Alcañiz, J., Kapteijn, F., Coudert, F.-X. \& Gascon, J. (2015). CrystEngComm, 17, 276-280.

Serre, C., Bourrelly, S., Vimont, A., Ramsahye, N. A., Maurin, G., Llewellyn, P. L., Daturi, M., Filinchuk, Y., Leynaud, O., Barnes, P. \& Férey, G. (2007). Adv. Mater. 19, 2246-2251.

Serre, C., Millange, F., Thouvenot, C., Noguès, M., Marsolier, G., Louër, D. \& Férey, G. (2002). J. Am. Chem. Soc. 124, 1351913526.

Shekhah, O., Wang, H., Paradinas, M., Ocal, C., Schüpbach, B., Terfort, A., Zacher, D., Fischer, R. A. \& Wöll, C. (2009). Nat. Mater. 8, 481-484.

Shepherd, H. J., Palamarciuc, T., Rosa, P., Guionneau, P., Molnár, G., Létard, J.-F. \& Bousseksou, A. (2012). Angew. Chem. Int. Ed. 51, 3910-3914.

Spek, A. L. (2009). Acta Cryst. D65, 148-155.

Spencer, E. C., Angel, R. J., Ross, N. L., Hanson, B. E. \& Howard, J. A. K. (2009). J. Am. Chem. Soc. 131, 4022-4026.
Spencer, E. C., Kiran, M. S. R. N., Li, W., Ramamurty, U., Ross, N. L. \& Cheetham, A. K. (2014). Angew. Chem. Int. Ed. 53, 55835586.

Spencer, E. C., Ross, N. L. \& Angel, R. J. (2012). J. Mater. Chem. 22, 2074-2080.

Spencer, E. C., Zhao, J., Ross, N. L., Andrews, M. B., Surbella, R. G. \& Cahill, C. L. (2013). J. Solid State Chem. 202, 99-104.

Sumida, K., Rogow, D. L., Mason, J. A., McDonald, T. M., Bloch, E. D., Herm, Z. R., Bae, T.-H. \& Long, J. R. (2012). Chem. Rev. 112, 724-781.

Tafipolsky, M. \& Schmid, R. (2009). J. Phys. Chem. B, 113, 13411352.

Tan, J. C., Bennett, T. D. \& Cheetham, A. K. (2010). Proc. Natl Acad. Sci. USA, 107, 9938-9943.

Tan, J. C. \& Cheetham, A. K. (2011). Chem. Soc. Rev. 40, 10591080.

Tan, J.-C., Civalleri, B., Erba, A. \& Albanese, E. (2015). CrystEngComm, 17, 375-382.

Tan, J. C., Furman, J. D. \& Cheetham, A. K. (2009). J. Am. Chem. Soc. 131, 14252-14254.

Tan, J. C., Merrill, C. A., Orton, J. B. \& Cheetham, A. K. (2009). Acta Mater. 57, 3481-3496.

Tidey, J. P., Wong, H. L. S., Schröder, M. \& Blake, A. J. (2014). Coord. Chem. Rev. 277-278, 187-207.

Torres, J. A. \& Velazquez, G. (2005). J. Food Eng. 67, 95-112.

Vaidhyanathan, R., Natarajan, S. \& Rao, C. N. R. (2003). Dalton Trans. pp. 1459-1464.

Volkringer, C., Loiseau, T., Guillou, N., Férey, G. \& Elkaïm, E. (2009). Solid State Sci. 11, 1507-1512.

Wang, Z. \& Cohen, S. M. (2009). Chem. Soc. Rev. 38, 13151329.

Wang, Z., Zhang, B., Inoue, K., Fujiwara, H., Otsuka, T., Kobayashi, H. \& Kurmoo, M. (2007). Inorg. Chem. 46, 437-445.

Williams, D. J., Partin, D. E., Lincoln, F. J., Kouvetakis, J. \& O'Keeffe, M. (1997). J. Solid State Chem. 134, 164-169.

Woodall, C. H., Beavers, C. M., Christensen, J., Hatcher, L. E., Intissar, M., Parlett, A., Teat, S. J., Reber, C. \& Raithby, P. R. (2013). Angew. Chem. Int. Ed. 52, 9691-9694.

Wu, Y., Kobayashi, A., Halder, G. J., Peterson, V. K., Chapman, K. W., Lock, N., Southon, P. D. \& Kepert, C. J. (2008). Angew. Chem. Int. Ed. 47, 8929-8932.

Wu, T., Zhang, J., Zhou, C., Wang, L., Bu, X. \& Feng, P. (2009). J. Am. Chem. Soc. 131, 6111-6113.

Xiao, B., Byrne, P. J., Wheatley, P. S., Wragg, D. S., Zhao, X., Fletcher, A. J., Thomas, K. M., Peters, L., Evans, J. S. O., Warren, J. E., Zhou, W. \& Morris, R. E. (2009). Nat. Chem. 1, 289-294.

Yaghi, O. M. \& Li, H. L. (1996). J. Am. Chem. Soc. 118, 295296.

Yakovenko, A. A., Chapman, K. W. \& Halder, G. J. (2015). Acta Cryst. B71, 252-257.

Yang, Q., Liu, D., Zhong, C. \& Li, J.-R. (2013). Chem. Rev. 113, 82618323.

Yang, S., Sun, J., Ramirez-Cuesta, A. J., Callear, S. K., David, W. I. F., Anderson, D. P., Newby, R., Blake, A. J., Parker, J. E., Tang, C. C. \& Schröder, M. (2012). Nat. Chem. 4, 887-894.

Zacher, D., Shekhah, O., Wöll, C. \& Fischer, R. A. (2009). Chem. Soc. Rev. 38, 1418-1429.

Zhang, C., Gee, J. A., Sholl, D. S. \& Lively, R. P. (2014). J. Phys. Chem. $C, \mathbf{1 1 8}, 20727-20733$.

Zhang, X.-M., Hao, Z.-M., Zhang, W.-X. \& Chen, X.-M. (2007). Angew. Chem. Int. Ed. 46, 3456-3459.

Zhang, J., Wojtas, L., Larsen, R. W., Eddaoudi, M. \& Zaworotko, M. J. (2009). J. Am. Chem. Soc. 131, 17040-17041.

Zhang, J., Wu, T., Zhou, C., Chen, S., Feng, P. \& Bu, X. (2009). Angew. Chem. Int. Ed. 48, 2542-2545.

Zhao, P., Bennett, T. D., Casati, N. P. M., Lampronti, G. I., Moggach, S. A. \& Redfern, S. A. T. (2015). Dalton Trans. 44, 44984503 . 
Zhao, P., Lampronti, G. I., Lloyd, G. O., Suard, E. \& Redfern, S. A. T. (2014). J. Mater. Chem. A, 2, 620-623.

Zhao, X. B., Xiao, B., Fletcher, A. J., Thomas, K. M., Bradshaw, D. \& Rosseinsky, M. J. (2004). Science, 306, 10121015.
Zheng, B., Pan, Y., Lai, Z. \& Huang, K.-W. (2013). Langmuir, 29, 8865-8872.

Zhou, W., Wu, H., Hartman, M. R. \& Yildirim, T. (2007). J. Phys. Chem. C, 111, 16131-16137.

Zhou, W. \& Yildirim, T. (2006). Phys. Rev. B, 74, 180301. 